Mundo Agrario vol. 18, no 37, e041, abril 2017. ISSN 1515-5994

Universidad Nacional de La Plata.

Facultad de Humanidades y Ciencias de la Educación.

Centro de Historia Argentina y Americana

\title{
La ideología sobre lo agrario de los productores rurales bonaerenses (2013)
}

\author{
The ideology about the agrarian of the farmers of Buenos Aires \\ province (2013)
}

\section{Javier Balsa *}

* Universidad Nacional de Quilmes. Consejo Nacional de Investigaciones Científicas y Técnicas, Argentina I jjbalsa@unq.edu.ar

\section{PALABRAS CLAVE}

Ideología

Productores rurales

Hegemonía

Encuesta

Buenos Aires

Conflicto agrario

\section{KEYWORDS}

Ideology

Farmers

Hegemony

Survey

Buenos Aires

Agrarian conflict

\section{RESUMEN}

Este artículo estudia la ideología de los productores rurales de la provincia de Buenos Aires a través del análisis de una encuesta realizada en el año 2013. En particular, se procura conocer la eficacia interpelativa que tenían las distintas discursividades sobre lo agrario que predominaban en la esfera pública, observar el grado de coherencia ideológica que poseían los productores rurales, y determinar la existencia (o no) de un sentido de separación a la hora de identificar los intereses propios en relación con los del resto de los productores. 
En las últimas décadas, el discurso público sobre la cuestión agraria ha sido hegemonizado por una particular combinación de una perspectiva tecnologizante (vinculada al discurso de los agronegocios) y de núcleos conceptuales liberal-conservadores. Sin embargo, el modelo socioeconómico que pregonan estas discursividades ha generado un fuerte proceso de concentración productiva que redundó en una drástica reducción en la cantidad de productores agropecuarios. De modo que cabe preguntarse en qué medida estos discursos, el liberal-conservador y el tecnologizante, logran que los productores rurales internalicen sus visiones del mundo rural y sus propuestas de cambio; en otras palabras, cabe preguntarse cuál es la eficacia interpelativa de estos discursos.

En este trabajo realizaremos un primer abordaje de esta problemática a partir del análisis de algunos de los datos de la Encuesta sobre la Ideología de los Productores Rurales bonaerenses que hemos llevado a cabo en 2013ํㅗㅇ. Más específicamente, nos proponemos estudiar la eficacia interpelativa de las distintas discursividades que predominan en la esfera pública, observar el grado de coherencia ideológica que poseían los productores rurales, y determinar la existencia (o no) de un sentido de separación a la hora de identificar los intereses propios en relación con los del resto de los productores.

\section{Discursividades sobre la cuestión agraria}

Históricamente se configuraron en nuestro país distintas concepciones sobre el agro y su lugar en el desarrollo nacional. En trabajos previos, hemos visibilizado cómo en los discursos públicos sobre el agro pampeano conviven actualmente en relación de contradicción y/o complementación tres discursividades que se diputan la hegemonía. Estas discursividades las hemos denominado liberal-conservadora, agrarista y tecnologizante, o de los agronegocios (Balsa, 2007).

La discursividad liberal-conservadora constituyó la base ideológica del modelo de apropiación privada -en grandes latifundios- de la tierra expropiada a los grupos indígenas a mediados del siglo XIX. Sin embargo, fue una enunciación “ausente”, en el sentido de que pocas veces formuló una defensa explícita del

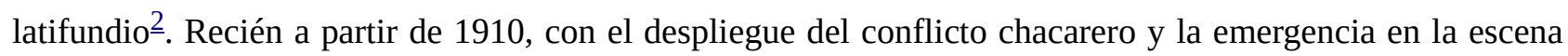
pública nacional de una discursividad agrarista crítica, el discurso liberal-conservador tuvo que aparecer más claramente en la disputa ideológica sobre la cuestión agraria. Desde mediados de los años treinta y hasta mediados de los cincuenta, sus posiciones fueron cada vez más defensivas. En este sentido, terminó compartiendo la formación discursiva agrarista: los objetos discursivos se definían esencialmente por su relación con la tenencia del suelo (Balsa, 2012) ${ }^{\underline{3}}$. Y, con la llegada del peronismo al gobierno, la enunciación liberal-conservadora tuvo que adoptar una estrategia completamente defensiva (Balsa, 2015).

Recién con el derrocamiento de Perón, esta discursividad liberal logró producir una enunciación que podemos catalogar como contraofensiva, ya que fue instalando una formación discursiva propia, de carácter liberal, en la que sus objetos pasaron a centrarse en la no regulación estatal de los mercados, y que pudo relegar a un segundo plano la cuestión de la tenencia del suelo (presentándola como una problemática ya superada $)^{4}$. En la actualidad, esta discursividad se caracteriza por la defensa del derecho absoluto de propiedad de la tierra y la no regulación estatal de los mercados (ya sea de tierras, de productos o de insumos).

Por su parte, la discursividad agrarista crítica se afianzó en las décadas de 1920 a 1940 y se caracterizó por contener una descripción muy negativa de la figura de los grandes propietarios, denominados casi siempre como terratenientes o latifundistas, y por presentar a los arrendatarios como explotados. También sostenía que esta situación no permitía el crecimiento del mercado interno, la democracia social y el desarrollo rural (Balsa, 2012). Además, formulaba duras críticas a la concentración del poder económico en manos de las grandes empresas cerealeras. Hacia mediados del siglo XX, algunas de sus apreciaciones sedimentaron en el 
lenguaje argentino, y llegaron a convertirse en parte del sentido común sobre la cuestión agraria, aunque siempre fueron combatidas desde el liberalismo-conservador. En los años sesenta y setenta, algunas modulaciones de este agrarismo se articularon con una discursividad de tipo revolucionario. Sin embargo, la última dictadura cívico-militar logró eliminar del discurso público la mayor parte de las enunciaciones agraristas. Luego, con el retorno de la democracia, esta discursividad no logró recuperar su fuerza (Lattuada, 1993) y, en los años noventa, quedó sumamente marginada en la opinión pública nacional. Sin embargo, a partir de la enorme crisis que golpeó a miles de pequeños y medianos productores -en torno al cambio de siglo-, el agrarismo crítico volvió a tener cierto espacio en la arena política y comunicacional. En las últimas décadas, este discurso fue incorporando una crítica a la concentración económica viabilizada a través de los pools de siembra y otro tipo de megaempresas agrícolas (que denominan como una agricultura sin agricultores) y también un cuestionamiento a las empresas multinacionales de insumos que se apropian de buena parte de los ingresos de los productores. En este sentido, es una discursividad favorable a una intervención estatal en los mercados (de tierras, de insumos y de productos) para asegurar la posición de los pequeños y medianos productores rurales.

Por último, desde los años sesenta fue emergiendo una discursividad diferente a las otras dos, que se centró en otro tipo de objetos: la tecnología y su celebración, y la adopción de una mentalidad empresarialinnovadora. Estos dos elementos fueron presentados como superadores de las antinomias entre liberales y agraristas (Gras, 2007; Balsa, 2010). Esta formación discursiva, que hemos denominado como tecnologizante o del agronegocio, en las últimas décadas se ha ido tornando cada vez más hegemónica, tanto en el discurso mediático (Carniglia, 2011), como entre las nuevas entidades agropecuarias (Hernández, 2013).

Esta discursividad tecnologizante, más allá de que en términos ideales podemos aislarla como una formación discursiva autónoma, en tanto construye sus propios objetos, en la práctica suele presentarse fuertemente articulada con elementos del discurso liberal-conservador (Liaudat, 2015).

\section{La ideología y su operacionalización}

Hemos trabajado con un concepto amplio de ideología, que considera que todo discurso es ideológico, en tanto cualquier enunciación externa nos interpela y propone una forma de ver el mundo y de criticar (o no) las situaciones de dominación, al tiempo que toda enunciación propia contribuye a la construcción de nuestra identidad (Voloshinov, 1929). $\underline{5}$

Zizek (2003, pp. 16-17), retomando a Hegel distingue tres momentos de lo ideológico: la doctrina (en tanto complejo de ideas), la creencia (que Zizek vincula con los aparatos ideológicos) y el ritual (como ideología “espontánea” que opera en el centro de la "realidad” social en sí, ejemplificada con el fetichismo de la mercancía, aunque el propio autor no esté seguro de emplear, en este caso, el término ideología). Al respecto, Gramsci había avanzado sobre la cuestión de cómo las formas de vida inciden en la construcción de la hegemonía, especialmente en el cuaderno sobre Americanismo y fordismo (Gramsci, 2000; Cuaderno 22). Algunas reflexiones sobre esta cuestión pueden encontrarse en nuestra conceptualización de una tercera lógica en la construcción de la hegemonía (Balsa, 2006a).

En este trabajo no abordaremos la cuestión de los aparatos ideológicos ni el plano del "ritual”, o modos de vida. El primero de estos temas ha sido poco estudiado; sin embargo, contamos con dos tesis doctorales, una centrada en el papel de los medios de comunicación de masas (Carniglia, 2011), y otra, en toda una serie de acciones de tipo "solidario" que construyen la hegemonía del discurso del agronegocio (Córdoba, 2015) ${ }^{6}$. El segundo tema, a saber, la manera en que las nuevas formas sociales de producción y los cambios en los modos de vida de los productores rurales incidieron -en un proceso recursivo- sobre la ideología de los 
productores, requeriría de otro tipo de estudios. Algunas elaboraciones sobre esta cuestión, al menos sobre cómo se estaba desplegando en las décadas del ochenta y noventa, pueden encontrarse en Balsa (2006b, capítulo cuarto).

En cambio, aquí analizaremos la ideología en tanto doctrina y también en tanto creencias poco estructuradas producto de su internalización asistemática. Es que, como sintetiza Hall, la identidad/identificación es el punto de encuentro entre los discursos y prácticas que intentan "interpelarnos", hablarnos o ponernos en nuestro lugar, y los procesos que producen subjetividades, que nos construyen como sujetos susceptibles de “decirse”. Son puntos de adhesión temporaria a las posiciones subjetivas que nos proponen las prácticas discursivas. (Hall, 2003, p. 20)

El concepto de interpelación es retomado explícitamente de Althusser (1970, p. 147), cuando señalaba que "toda ideología interpela a los individuos concretos como sujetos concretos, por el funcionamiento de la categoría de sujeto". "Los individuos son siempre-ya interpelados por la ideología como sujetos [...] Por lo tanto los individuos son 'abstractos' respecto de los sujetos que ellos mismos son siempre-ya” (148). Y, como agregó luego Therborn (1991, p. 64), los individuos son interpelados como partícipes de innumerables papeles sociales y no son necesariamente coherentes en sus recepciones y en sus acciones de respuestas. De algún modo ya Gramsci había pensado las subjetividades como una puja entre las diversas "hegemonías" y había propuesto para el sujeto un papel (auto)crítico sobre su propia conciencia: "La comprensión crítica de sí mismos se produce pues a través de una lucha de 'hegemonías’ políticas, de direcciones contrastantes, primero en el campo de la ética, luego de la política, para llegar a una elaboración superior de la propia concepción de lo real.” (Gramsci, 1986, p. 253).

De todos modos, retomando la definición de Gerring (1997), diremos que una discursividad constituye una ideología en la medida en que hay cierta "coherencia" o "sistematicidad" interna en las ideas, creencias o representaciones, y luego los sujetos pueden mantener en sus creencias o representaciones esta coherencia o, mucho más habitualmente, construir una combinación de elementos de ideologías diferentes. Entonces, en algunos casos, las interpelaciones pueden lograr identificaciones plenas y relativamente "dogmáticas" por parte de los sujetos, en tanto incorporan una visión más o menos estructurada del mundo. Pero en otros casos, estas identificaciones ideológicas son más caóticas, ya que internalizan solo algunas frases formulísticas (Phillips, 1998) sin que necesariamente se comparta una conceptualización sistemática, aunque en algunos casos fuera posible hallar algunos elementos estructuradores que le otorgan cierta lógica a la mayoría de las apreciaciones.

Incluso las propias ideologías, en tanto son "procesos sociales en curso", siempre operan con cierto grado de desorden (Therborn, 1991). Finalmente, en el proceso interpelativo, la propia construcción de cadenas equivalenciales (centro de la operación hegemónica) está imbuida de relaciones de ambigüedad, ya que toda equivalencia no puede ser una mera identidad (Laclau y Mouffe, 1987).

Las tensiones entre visiones opuestas del mundo no solo surgen del choque entre discursividades públicas, sino que también emanan de la propia práctica de interacción con la realidad. Gramsci planteaba que la “conciencia teórica incluso puede estar históricamente en contraste con su actuar. Casi puede decirse que tiene dos consciencias teóricas (o una conciencia contradictoria), una implícita en su actuar y que realmente le une a todos sus colaboradores en la transformación práctica de la realidad, y una superficialmente explícita o verbal que ha heredado del pasado y ha acogido sin crítica”. Y para este autor, la conciencia que surge de la práctica estimula el desarrollo del "buen sentido", o sea, “el núcleo sano del sentido común” (Gramsci, 1986, pp. 249-253).

Este “buen sentido” sería también la causa del "sentido de separación” del que hablaba Sorel: la concepción espontánea del mundo de las clases subalternas incluye siempre un "sentimiento elemental de separación” 
que puede o no resolverse en una conciencia del antagonismo social, de la oposición entre dominantes y dominados (Nun, 1989).

Entre los numerosos estudios sobre la ideología desarrollados a través de encuestas, el presente trabajo se vincula más específicamente con tres tradiciones: los trabajos con encuestas de la denominada Escuela de Frankfurt; la investigación de José Nun sobre las significaciones del peronismo, y una serie de trabajos sobre la ideología en la actualidad latinoamericana que indagan acerca de la eficacia interpelativa de las propuestas político-ideológicas del neoliberalismo y de las distintas fuerzas de izquierda o centro-izquierda.

En cuanto a los trabajos de Fromm (1939/2012), Fromm y Maccoby (1979/1992) y de Adorno et al. (1965), más allá de las diferencias entre ellos, es posible visualizar importantes puntos de acuerdo en su perspectiva. De esta tradición, recuperamos la idea de que, además de describir las frecuencias en las respuestas a cada pregunta, es posible identificar "síndromes" de actitudes a partir del análisis del conjunto de todas las contestaciones. Estos síndromes permitirían determinar -al vincular estos patrones con las propuestas doctrinales- el grado de eficacia que cada ideología logra en los distintos tipos de sujetos, aunque se debe también atender a las peculiaridades de cada personalidad. Para ello, estos autores han sido pioneros en el trabajo con técnicas estadísticas de análisis multivariados, que usaban con el fin de encontrar regularidades en las respuestas y hallar factores comunes o síndromes. Esta tradición ha ubicado en un nivel explicativo más profundo el carácter social y el tipo de personalidad de los sujetos. Estos factores, en tanto disposiciones a la acción, incidirían sobre la conducta de los sujetos más allá de los acuerdos doctrinarios que ellos hayan explicitado $^{\underline{7}}$. Sin embargo, por limitaciones propias del tipo de encuesta que hemos desarrollado, no hemos podido avanzar sobre estas cuestiones propias del carácter social o la personalidad de los productores rurales. Algunas reflexiones sobre el carácter social de los productores rurales y su transformación durante el siglo XX pueden encontrarse en nuestro trabajo hecho sobre la base de entrevistas en profundidad, aunque en el mismo no hemos podido trascender el nivel de las hipótesis interpretativas (Balsa, 2006b, capítulo cuarto).

En segundo lugar, recuperamos la tradición de Nun (1984) en su trabajo sobre las significaciones que los obreros tenían acerca del peronismo. Allí se propone ir más allá de los marcos de la sociología positivista al emplear la técnica de la encuesta. Desde un enfoque interpretativo, Nun se propuso la recreación de juegos de lenguaje que les fueran familiares a los entrevistados, y que incluían preguntas abiertas y estímulos visuales. Para entender las significaciones del peronismo, entre otras cuestiones, trató de captar a quiénes definían los entrevistados, en tanto trabajadores, como individuos que tuvieran problemas e intereses similares a los suyos. Y, más específicamente, procuró determinar en qué medida se combinaban en los razonamientos una cierta imagen de la homogeneidad de intereses y una visión antagonista de los ricos y/o de los patrones. Específicamente, de esta perspectiva recuperaremos el análisis sobre los tipos de sujetos agrarios que los entrevistados consideraban como poseedores de intereses iguales, relativamente similares o diferentes a los suyos.

En tercer lugar, hemos retomado cierta tradición de estudios sobre la ideología en la actualidad desarrollados en América Latina, los cuales se centran en indagar las actitudes en favor o en contra de la intervención del Estado, y que trabajan a partir de las frases programáticas de las principales corrientes de pensamiento político presentes en la región. Para ello, revisamos desde los trabajos de Mora y Araujo (1985), hasta aquellos más actuales, como los de Gálvez Vera y Terceros Pavisich (2009), Brussino et al. (2011), Ibarómetro (2015), entre otros ${ }^{\underline{8}}$.

\section{La estrategia muestral y las características generales del cuestionario}

Antes de comenzar el análisis, consideramos importante explicitar las herramientas y procesos utilizados para obtener la información buscada. Se planificó una muestra de 396 casos a partir de los cuales finalmente 
se pudieron concretar 329 encuestas. La muestra no fue probabilística, ya que, por un problema de escasez de fondos, los casos fueron seleccionados por cuotas y no al azar. Para controlar -en la medida de nuestras posibilidades- los sesgos se garantizó la representatividad y proporcionalidad de casi todas las zonas

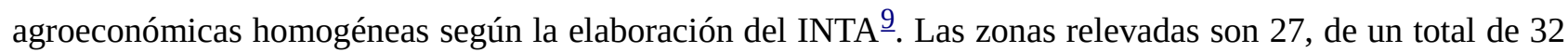
zonas agroecológicas homogéneas de la provincia de Buenos Aires. Por una cuestión de especificidades agroproductivas hemos dejado de lado la zona del Delta y la del Gran Buenos Aires. Luego hubo tres zonas que, si bien procuramos cubrir en el relevamiento, no pudieron ser incluidas por problemas logísticos (Zárate, Trenque Lauquen y Chillar). Finalmente, cabe aclarar que en una zona (General Conesa) se realizaron solo la mitad de las encuestas previstas (ver Mapa 1).

El trabajo por zonas no pretende realizar análisis con aperturas por zonas al interior de la provincia, pero sí contar con una muestra representativa del conjunto y de las diversidades zonales. En cada zona se efectuó el trabajo de campo en un único partido; pero justamente por ser zonas homogéneas, resulta muy plausible que cualquier partido sea relativamente representativo de la zona de la que forma parte. El número de casos por zona es proporcional a la cantidad de explotaciones que cada zona tenía en 2002, según los datos del censo agropecuario realizado en dicho año. En este sentido, se presupuso que el proceso de concentración que tuvo lugar entre ese momento y 2013 ha sido relativamente homogéneo en todas las zonas (un supuesto plausible que, además, no puede ser revisado para ajustar la muestra de otra manera).

A falta de un listado muestral, y ante las dificultades de implementación del trabajo de campo con los pocos recursos disponibles, no se pudo realizar un muestreo probabilístico, y se implementó un muestreo por cuotas en el interior de cada zona. Para garantizar la representatividad de los distintos tipos de productores se utilizaron cuotas con base en cuatro variables:

1. Por tamaño de las explotaciones, respetándose la distribución presente en cada zona en 2002, y con un ajuste según un plausible proceso de concentración (según los estratos de menos de 50, de 50 a 250, de 250 a 500, de 500 a 1.200 y más de 1.200 hectáreas) ${ }^{10}$.

2. Por la tenencia del suelo (propietarios, mixtos y no propietarios), según la distribución existente en cada zona en 2002 (no se pudo estimar su variación relativa entre 2002 y 2013)

3. Según el uso del suelo (predominantemente agrícolas, agrícolas/ganaderos, ganaderos/agrícolas, y predominantemente ganaderos), según la distribución de 2002 ajustada por el proceso de agriculturización que sufrió cada zona $\underline{11}$.

4. Una cuota de género según los datos de 2002 del conjunto de la provincia (85 \% de hombres y $15 \%$ de mujeres) $\underline{12}$.

Los encuestadores fueron un grupo de mujeres y hombres, en su mayoría estudiantes universitarios o graduados recientes de carreras de ciencias sociales o de agronomía cuyas familias residían en las zonas (lo cual permitió reducir sustancialmente los gastos). Entonces comenzaron la muestra a partir de contactos personales, pero luego procuraron distanciarse de dichos conocidos para garantizar mayor diversidad. El criterio general de selección de los casos era que debería tratarse hombres o mujeres que estuvieran a cargo de una explotación agropecuaria, pero debían respetar las cuotas establecidas en cada zona.

El cuestionario se elaboró sobre la base base de una revisión y actualización de un cuestionario de carácter exploratorio aplicado en 2006 a productores de Ayacucho y Pehuajó $\frac{13}{}$. En primer lugar, se realizaron los ajustes aconsejados por la detección de problemas en el trabajo de campo y en el análisis de esta primera encuesta. En segundo lugar, se incorporaron nuevos interrogantes. Y, por último, se efectuó un pretesteo 
cognitivo del nuevo borrador de cuestionario y, finalmente, un pretesteo de tipo tradicional $\frac{14}{}$. Ambos trabajos se realizaron durante 2012 con productores de la zona de Junín, y fueron llevados adelante por Carolina Sarobe en el marco de la realización de su tesina de licenciatura en sociología.

El cuestionario finalmente aplicado contiene 28 preguntas abiertas y 66 preguntas cerradas. Al momento de elaborar este artículo aún no hemos podido codificar todas las preguntas abiertas, de modo que nos centraremos en el análisis de las preguntas cerradas y en cuatro preguntas abiertas.

\section{Las discursividades “espontáneas”}

Casi al comienzo de la encuesta, a fin de obtener respuestas en las que no incidieran los enunciados de las preguntas que después se harían, se colocaron una serie de preguntas abiertas cuyas respuestas fueron transcriptas textualmente y luego codificadas en un proceso de dos etapas. De todos modos, esto no significa que sus contestaciones fueran espontáneas, en el sentido de que emergieran como parte del discurso cotidiano de los productores sino que, por el contrario, surgían en un contexto sumamente artificial como lo es toda encuesta social estructurada. Sin embargo, las respuestas no debían escogerse de una lista cerrada de opciones, ni tampoco estaban condicionadas por preguntas previas que hubieran instalado determinadas formas de hablar sobre las cuestiones agrarias. Es por este motivo que empleamos el término espontáneas, pero entre comillas.

Un primer grupo de preguntas solicitaba que dijeran una frase a partir de una palabra $\frac{15}{}$. De las once palabras preguntadas, hemos analizado dos para este trabajo: pools de siembra y Monsanto. En relación con los pools de siembra, como se observa en la Tabla 1 , casi dos tercios de los entrevistados formuló frases relativamente negativas acerca de los pools. Algunas eran muy negativas (18\%), del tipo "una locura”, "buitres”, "nos mata a todos", "tendrían que desaparecer”; otras respuestas eran simplemente negativas, del tipo "mal” (12 $\%)$, y en otros valores agrupamos las respuestas que criticaban a los pools porque perjudican a los productores más chicos y a los arrendatarios (13\%), o generan concentración (6\%) o no cuidan el suelo (1\%). Un 9 \% deslizó críticas relativas (“capitales extranjeros”, “aumentaron los alquileres”, "gran negocio”, “no son gente de campo", etc.).

En el extremo opuesto, encontramos algo menos de la décima parte de los productores que ubicaron a los pools en frases positivas, de tipo "son necesarios", “aportan capital”, "si no molestan, están bien". Y, por último, podemos destacar que un $16 \%$ formuló descripciones neutras (que en general planteaban en qué consisten los pools, pero no agregaban ningún tipo de valoración o posicionamiento del entrevistado en relación con ellos) y que un $6 \%$ los vinculaba con el gobierno-Estado (porque crecieron apoyados por el gobierno o porque se sostenían en evasiones impositivas). Corresponde señalar que el nivel de no respuesta fue notoriamente bajo (8\%), lo cual, sumado a que solo un $16 \%$ tuvo respuestas neutras, indica que la enorme mayoría de los productores tiene posición tomada frente a los pools.

En cuanto a la palabra disparadora Monsanto, como se puede ver en la Tabla 2, las posiciones estuvieron mucho más repartidas entre aquellos que fueron sumamente críticos (20\%), algo críticos (20\%) y los que poseían una mirada positiva que destacaba el aporte tecnológico que haría esta empresa líder (30\%). Cabe señalar que un $15 \%$ brindó respuestas neutras, del tipo "una empresa”, y un 14 \% no contestó, cuando difícilmente no supiese qué es Monsanto.

Luego de la serie de palabras “disparadoras” (en total, once), se incluyó una pregunta para ver cómo conceptualizaban a los distintos tipos de productores agropecuarios, es decir, cuál era la forma en que los diferenciaban. Para ello, se recurrió a una formulación sumamente compleja que buscaba evitar incidir en las respuestas, al mismo tiempo que todos los entrevistados tuvieran claro qué información se les estaba solicitando: "Si viniera alguien que no sabe nada del campo y le preguntara qué diferentes tipos de 
productores existen en el campo, así como de las vacas le podría decir que están las Shorton, las Heresford y otras razas ¿cuál sería la principal diferenciación que usted haría entre los productores agropecuarios? Usted diría que "están estos y aquellos..."

Las variadas respuestas fueron codificadas y recodificadas, y se obtuvieron los resultados de la Tabla 3; se destaca además que prácticamente todos contestaron. Podemos observar que un $39 \%$ propuso diferenciaciones basadas en el tamaño (pequeños, medianos y grandes, o pequeños y grandes). También, con un tono crítico a la presencia de inversores externos, un 15 \% destacó la diferenciación en relación con los que viven del campo y/o trabajan la tierra y, por otro lado, los que tienen otros negocios y/o no trabajan la tierra. De modo que, aunque la diferenciación por la tenencia del suelo prácticamente no tuvo registros, la perspectiva que destaca la importancia de la extensión de las unidades o el trabajo directo sumó más de la mitad de los entrevistados; esto evidencia que el discurso que plantea que esas no son dimensiones importantes para distinguir a los productores había tenido una reducida eficacia interpelativa entre los productores agropecuarios bonaerenses.

Otro grupo importante (33 \%) centró la diferencia en el perfil productivo (agrícolas o ganaderos), mientras que solo un 4,5 \% los distinguió según fueran innovadores o tradicionales (lo que devela una escasa eficacia interpelativa del discurso tecnologizante a la hora de diferenciar a los sujetos).

En otra parte de la encuesta, se les leía y mostraba una tarjeta con la frase La tierra para el que la trabaja y se les preguntaba “¿qué le parece que quiere decir y qué opina de eso?” La gran mayoría de los entrevistados (70 \%) remitieron claramente al significado histórico de la frase, en su sentido crítico del latifundio y favorable a la implementación de procesos de colonización o reforma agraria que le dieran la tierra a quienes la trabajaban (tanto arrendatarios como aparceros). Como se observa en la Tabla 4, unos se manifestaban en contra de estas políticas agraristas (32 \%), y otros a favor (23\%), mientras que otro grupo solo brindó un acuerdo moderado: algunos de forma parcial o enfocado en colocar frenos a los compradores extranjeros, en general aclarando que no acordaban con las expropiaciones (5\%), y otros que manifestaron un acuerdo con la frase, pero aclarando que era una idea utópica (5 \%).

Llamó la atención que, además de este 70 \% que había remitido al significado histórico de la frase, algo más de un quinto de los entrevistados (22 \%) resignificó el sentido de la misma y le dio una intención crítica solamente hacia aquellos propietarios que dejaban los campos improductivos ("la tierra tiene que ser trabajada”). De este modo, pudieron manifestar su acuerdo con la frase, pero aliviada de todo contenido redistributivo. Cabe aclarar que un pequeño porcentaje resignificó el sentido de la frase, pero aun así no acordó con la misma (4 \%).

Por último, se destacan los reducidos porcentajes de no respuesta (2 \%) o de manifestaciones de entrevistados que dijeron no entender el significado de la frase (2\%), y la presencia de un último grupo que no se posicionó frente a la misma (5\%)

De modo que ha sido posible observar que un enunciado "clásico" de la discursividad agrarista crítica, como es la frase la tierra para el que la trabaja, mantiene cierta vigencia en su interpelación a los productores rurales. Consideramos que lo logra, más que en términos de adhesiones explícitas a un ideal de reforma agraria, en términos de que a la mayoría le es muy difícil enunciar un rechazo a una frase que apela una idea básica de distintas ideologías (incluso de la tradición liberal, véase Locke, 2003), que fundamenta la propiedad en el trabajo de la misma. Si sumamos los distintos tipos de adhesiones, totalizan un $57 \%$ de los entrevistados. Pero, del total que adhirió, solo el 40 \% estaba claramente de acuerdo con el sentido de la frase, mientras que un 19 \% acordó solo parcialmente con la frase o la consideró correcta pero utópica, y otro 40 \% resignificó el sentido de la frase hacia la idea (sin connotaciones redistributivas) de que pudieran dejarse campos sin producir. 
Hemos estudiado las posibles relaciones en las respuestas a estas cuatro preguntas abiertas, considerándolas de a pares. Sin embargo, las relaciones resultaron ser sumamente pequeñas, es decir, que no fue posible hallar patrones de respuestas vinculadas.

\section{Los grados de acuerdo con frases típicas de las discursividades liberal-conservadora,teconologizante o del agronegocio, y agrarista}

Se les pidió a los hombres y las mujeres entrevistadas que dijeran cuán de acuerdo estaban con una serie de frases típicas de las tres principales discursividades sobre cuestiones agrarias que existen en el debate público argentino. En las tablas 5, 6 y 7 se reproducen textualmente las frases leídas, además de los porcentajes de respuestas. En líneas generales, cada frase buscaba tener un efecto interpelativo "seductor”; es por ello que estaban formuladas de manera de concitar la adhesión a las mismas, con términos que contuviesen motivos argumentales que favorecieran ese acuerdo. Las opciones de respuesta eran Totalmente de acuerdo, Medianamente de acuerdo, Solo un poco de acuerdo o Nada de acuerdo. Existía la opción de no contestar, pero no era leída a los entrevistados, y en muy pocos casos no hubo respuesta. Siete de estas frases caracterizaban el discurso agrarista, tres el discurso liberal-conservador, y cuatro el tecnologizante o de los agronegocios. Se procuró que la mayoría de las cuestiones fueran abordadas desde dos de las discursividades, de modo que se pudiera ver la eficacia interpelativa de un mismo tema desde posiciones opuestas.

\section{1. Acuerdo/desacuerdo con las frases liberal-conservadoras}

Como se observa en la Tabla 5 , se destaca un altísimo grado de acuerdo con las frases típicas del discurso liberal-conservador, en particular el respeto por la propiedad y la decisión individual del uso del suelo; en cambio, la adhesión, aunque clara, fue un poco menos directa en relación con la desregulación de los mercados, pues hubo bastantes entrevistados que solo estuvieron medianamente de acuerdo, y un quinto estaba solo un poco o nada de acuerdo.

Hemos estudiado las correlaciones que existen entre las respuestas a estas tres frases liberal-conservadoras. Para el cálculo de estas correlaciones, como así también de las subsiguientes, se consideró que las respuestas formaban una escala acorde con los siguientes valores numéricos: 1 para cada respuesta Totalmente de acuerdo, 0,66 para Medianamente, 0,33 para Solo un poco y 0 para Nada. De modo que, más allá de los debates acerca de las limitaciones de tratar una escala (en principio ordinal) en términos de intervalo, nos hemos inclinado por explorar su posible transformación, ya que nos parece plausible que la mayoría de las personas entrevistadas tuvieran en mente distancias similares a estas cifras.

Por otro lado, también hemos optado por hacer uso del coeficiente de correlación de Pearson para variables escalares (en relación con esta transformación numérica), siguiendo una tradición usual en la sociología, pero que en las últimas décadas ha obtenido aval respecto de su pertinencia estadística a partir de estudios comparativos con técnicas escalares (Norman, 2010; Murray, 2013).

Regresando al estudio de las relaciones entre los tres grados de acuerdo con las frases liberalesconservadoras, podemos decir que llamativamente las correlaciones no son muy elevadas: con coeficientes de entre 0,02 y 0,33, aunque cabe señalar que, como veremos, en líneas generales las correlaciones entre las 14 frases son bastante bajas (ver datos en la Tabla 1 del Anexo). $\underline{16}$

\section{2. Acuerdo/desacuerdo con las frases del discurso "tecnologizante” o de los "agronegocios”}

Como se observa en la Tabla 6, dos frases del discurso que hemos denominado como de los agronegocios 
tuvieron un importante nivel de adhesión: la que destaca el conocimiento frente al tamaño para ser competitivo, y la que plantea que las tecnologías mejoraron a todos los productores. Sin embargo, no todos estuvieron totalmente de acuerdo, sino que un importante porcentaje solo estuvo medianamente de acuerdo, e incluso en el caso de los efectos benéficos de la tecnología para todos, una quinta parte de los entrevistados dijo estar solo un poco de acuerdo o nada de acuerdo con la frase.

Como se observa en la misma tabla 6 , las otras dos frases de los agronegocios tuvieron un nivel de adhesión mucho menor. Merece destacarse que la frase que planteaba: Dentro de la cadena agroindustrial, los productores agropecuarios, los industriales y comerciantes tienen los mismos intereses presentó un alto nivel de rechazo: entre solo un poco de acuerdo y nada de acuerdo suman un $60 \%$. Cabe señalar, sin embargo, que según comentaron los/as encuestadores/as, esta frase presentó en algunos casos problemas de comprensión.

Las correlaciones entre todas las frases de la discursividad de los agronegocios son llamativamente reducidas: con coeficientes de entre el 0,10 y el 0,23, tal como puede apreciarse en la Tabla 1 del Anexo $\frac{17}{\text {. }}$

\subsection{Acuerdo/desacuerdo con las frases “agraristas”}

Algunas de las frases agraristas tuvieron un importante nivel de adhesión, como la de la necesidad de leyes que frenen la concentración y la de la calificación de verdaderos productores solo a aquellos que trabajan efectivamente en el campo, con adhesiones en torno a los tres cuartos de los entrevistados si computamos las respuestas Totalmente y Medianamente de acuerdo (ver Tabla 7). Incluso, llamativamente, fue bastante elevada la adhesión al mantenimiento de las retenciones pero enmarcadas en una política redistributiva, con dos tercios de los entrevistados que se manifestaron total o medianamente de acuerdo.

Un poco menor fue la adhesión a la frase que afirma: muchos pequeños productores han desaparecido a causa del cambio tecnológico, aunque algo más de la mitad estuvo total o medianamente de acuerdo. De un modo similar se comportaron las respuestas en relación con la idea de que el Estado debe regular el uso del suelo para evitar que se deteriore un recurso que es de todos los argentinos. Mucho menor fue el acuerdo con las frases en las que se reclama la intervención del Estado en el mercado, ya sea en el de arrendamiento o en el de granos. En este último caso, se observan posturas polarizadas, siendo más altas las frecuencias en las respuestas totalmente o nada de acuerdo.

Las correlaciones entre las siete frases agraristas son en general bajas (la mayoría de los coeficientes se ubican en torno al 0,2), aunque existen algunas excepciones que indican la presencia de acuerdos parciales, más que grandes adhesiones ideológicas a los postulados agraristas $\underline{18}$.

\section{4. Las relaciones entre los acuerdos con las distintas frases y patrones de respuestas a las mismas}

El análisis de la matriz de correlaciones, que se reproduce en la Tabla 1 del Anexo, mostró bajas asociaciones en el interior de cada discursividad (tal como ya hemos comentado), pero más llamativamente, también en el esperable sentido negativo de las frases contrapuestas, al menos parcialmente. Es decir que no surgieron las relaciones negativas que se aguardaba encontrar entre las respuestas a las frases de perspectivas ideológicas opuestas. Así, por dar solo un ejemplo de estas inconsistencias ideológicas, la correlación entre Las nuevas tecnologías mejoraron mucho la situación de todos los productores rurales y Muchos pequeños productores han desaparecido a causa del cambio tecnológico ha sido de -0,005. Este coeficiente sintetiza una distribución en la cual no hay una asociación negativa entre las respuestas a ambos enunciados, a pesar de que eran relativamente contradictorios. Esto es así pues predominaron los acuerdos o rechazos simultáneos: casi la mitad de los entrevistados estaba total o medianamente de acuerdo con ambas frases, y una décima 
parte no estaba nada o solo un poco de acuerdo con los dos enunciados. En cambio, algo menos de la mitad manifestó cierta coherencia: un 34 \% estuvo de acuerdo con la primera de las frases y rechazó la segunda, y un 12 \% suscribió la primera y disintió con la segunda.

Del análisis de todas las asociaciones que esperábamos fueran negativas, entre frases contrapuestas de las distintas discursividades solo son destacables, aunque no elevadas, algunas relaciones:

1. de la frase sobre el derecho sagrado de la propiedad y tres frases agraristas: que el Estado regule los arrendamientos $(-0,23)$, que regule el uso del suelo $(-0,25)$ y que son necesarias leyes que frenen la concentración $(-0,19)$;

2. entre la desregulación de los mercados y la regulación de los arriendos $(-0,18)$;

3. entre las dos frases contrapuestas sobre el uso del suelo $(-0,17), y$

4. entre la visión positiva de las nuevas tecnologías y la recreación de las Juntas $(-0,13)$.

En cambio, aparecen relaciones levemente positivas entre una serie de frases de los agronegocios y frases agraristas, lo que sin dudas muestra la escasa estructuración de las ideas de los entrevistados, ya que muchas de las frases abordaban los mismos tópicos aunque se oponían en su valencia.

Para tratar de reducir la cantidad de dimensiones (desde las 14 variables-frases a un número menor de variables), se aplicaron algunos análisis, empleando métodos de componentes principales y análisis factorial, pero la baja correlación entre las variables determinó que los componentes o factores lograban una reducida explicación de la variabilidad total: incluso con cuatro componentes principales, apenas se llegaba a captar el $49 \%$ de la variabilidad total presente en las catorce variables $\underline{19}$. Por esta escasa eficacia se descartaron los resultados de estos procesos. Dichos procedimientos solo confirmaron la poca coherencia ideológica que presentan los productores en relación a las tres discursividades que se destacan en la opinión pública.

También se practicaron análisis de clusters, que no requerían de presupuestos acerca de alineamientos claros en torno a las distintas discursividades $\underline{20}$. Luego de varios ensayos, se optó por el resultado del análisis de conglomerados jerárquicos, con método de conglomeración por vinculación intragrupos y distancia euclidea al cuadrado, y se seleccionó el resultado de seis conglomerados. De todos modos, los grupos conformados combinaban adhesiones y rechazos a conjuntos no muy coherentes de frases, pero sobre todo presentaban elevada disparidad en sus patrones de respuesta, todo lo cual hacía muy difícil su descripción en términos interpretativos.

Finalmente, hemos optado por un método de análisis más detenido, que coteja las respuestas a las frases contradictorias. Para ello, recuperamos un tipo de análisis utilizado por Fromm en su estudio sobre los obreros y empleados en vísperas del Tercer Reich, cuando identificaba los síndromes de personalidad a partir de la presencia de grados de consistencia en las respuestas para cada grupo de preguntas (Fromm, 1939/2012). Así, por ejemplo, aunque solo 28 de los 584 cuestionarios mostraron respuestas plenamente consistentes en las cuatro preguntas seleccionadas para caracterizar las visiones políticas, Fromm identificó como radical el cuestionario en el que al menos una respuesta fue clasificada como radical y en ninguna de las otras tres preguntas se manifestó una actitud autoritaria. Clasificó como autoritario a quien respondió al menos una pregunta de esta forma, mientras que ninguna hubiera tenido una contestación radical; como orientada al compromiso, con respuesta de este tipo y sin ninguna radical o autoritaria, y como indiferente, en los casos en que hubiera algún tipo de combinación entre respuestas radicales, autoritarias y/o de compromiso o indiferentes. Según su explicación, "en la medida en que los resultados particulares no eran notoriamente contradictorios, caracterizamos el complejo en cuestión en su totalidad con aquella letra que correspondía a la mayoría de sus respuestas parciales” (Fromm, 1939/2012, p. 320). 
Avanzamos, entonces, con una estrategia similar que se basa en distinguir grupos a partir de detectar si las respuestas de cada entrevistado se oponían en las frases contrapuestas, o si por el contrario, adherían a ambas frases o rechazaban ambas.

Se construyeron nuevos índices con pares de frases, aquellas que más claramente se contraponían (de un lado la agrarista, y del otro la liberal-conservadora o la tecnologizante). De este modo, procuramos mensurar el grado efectivo de adhesión a cada frase-posición ideológica. La metodología de análisis partió de la dicotimización de las respuestas: unificando por un lado el acuerdo (sumando Totalmente y Medianamente de acuerdo) y, por otro lado, el desacuerdo (agregando Solo un poco y Nada de acuerdo). Luego se asignaron distintos valores según hubieran manifestado alguna de las cuatro posiciones posibles: (1) acuerdo con la agrarista y desacuerdo con la liberal o la tecnologizante; (2) acuerdo con la liberal o tecnologizante y desacuerdo con la agrarista; (3) acuerdo con ambas frases, o (4) desacuerdo con ambas. Las posiciones (3) y (4) las hemos considerado como neutras o neutralizadas.

Como resultado de este procedimiento, consideramos que hemos obtenido indicadores de mayor confiabilidad y validez, ya que se computa a un entrevistado en una posición únicamente en el caso en que no solo haya adherido a una frase, sino que haya rechazado la contraria, es decir, las posiciones (1) o (2).

En el caso del eje liberal/agrarista no teníamos una oposición una a una de cada frase, sino que una frase se contraponía a varias del otro eje, de modo que hubo que repetir las respuestas de algunas frases para construir el contrapunto. Así, se construyó la siguiente contrastación: por un lado, "El Estado debe regular el uso del suelo..." opuesto a "El derecho de la propiedad de la tierra es sagrado..." y también a "Solo los productores deben decidir qué y cómo se produce en su tierra”, y por otro lado, "Los mercados tienen que estar completamente desregulados" contrapuesto a "El Estado... juntas de carne y granos”, a "El Estado tiene que regular el mercado de los arrendamientos...", a "Son necesarias leyes que frenen la concentración de la tierra ...” у а "Hay que mantener las retenciones pero...”. De este modo, obtuvimos seis nuevos índices para el eje liberal-agrarista.

En el caso del eje tecnologizante-agrarista, que pasamos a denominar tecnologizante-crítico tecnológico, obtuvimos dos índices. En uno se opusieron las respuestas a las frases sobre el efecto del cambio tecnológico: Las nuevas tecnologías mejoraron mucho la situación de todos los productores rurales y Muchos pequeños productores han desaparecido a causa del cambio tecnológico. Y en el otro índice se consideraron las contestaciones acerca de qué es un productor rural: "Los verdaderos productores son los que trabajan efectivamente en el campo" y "Los productores agropecuarios ya no son chacareros sino que son empresarios”.

En todo este análisis, hemos dejado de lado dos frases que observamos que tuvieron algunos problemas de comprensión por parte de los entrevistados, y que sobre todo no presentaban una clara interpretación acerca de su sentido en los ejes construidos. Así, en la frase "hoy en el campo argentino el más competitivo no es el más grande, sino el que mejor sabe hacer", no nos quedaba del todo claro si la habían respondido como descripción, o como valoración. Y la frase "Dentro de la cadena agroindustrial... tienen los mismos intereses” tuvo problemas de interpretación por parte de los entrevistados. Además, estas dos frases no presentaban una frase contrapuesta para validarlas en este nuevo eje.

$\mathrm{Al}$ analizar las frecuencias en el eje liberal/agrarista, encontramos que solo un 0,5 \% manifestó posiciones claramente agraristas en los seis índices, mientras que un 1,9 \% adhirió a los seis índices de forma liberalconservadora. Por lo tanto, hemos flexibilizado los criterios de agregación, e incluimos en cada categoría a aquellos en los que se observaba un predominio de las adhesiones coherentes a cada discursividad, al tiempo que en el resto de los índices se encontraban posiciones neutralizadas. De este modo, los predominantemente agraristas sumaron un $14 \% \underline{\underline{21}}$. En el extremo opuesto, la agregación de entrevistados que manifestó 
respuestas predominantemente liberal-conservadoras alcanzó el 53,5 \% de la muestra $\underline{22}$. En el medio, quedaron un $31,5 \%$ de entrevistados que tuvieron respuestas mayoritariamente neutralizadas (26\% que adhirieron a la mayoría de las frases, un 3 \% que rechazó la mayoría y otro 3 \% que adhirió a algunos índices de forma agrarista y a otros de forma liberal).

De este modo, si simplificamos la variable en tres posiciones, tenemos un $14 \%$ de agraristas, un 53,5 \% de liberal-conservadores, y 31,5 \% de "neutros".

En el eje tecnologizante-crítico tecnológico, encontramos un 3,4 \% de entrevistados con los dos índices claramente críticos y un 6,4 \% con ambos índices tecnologizantes. A los críticos agregamos un 25,5 \% que tuvieron un índice crítico y otro con respuestas neutralizadas, y suman en total un $29 \%$ con respuestas relativamente críticas. Por su parte, el 24,4 \% que tuvo un índice tecnologizante y el otro con respuestas neutralizadas fue sumado a los completamente tecnologizantes, por lo cual los relativamente favorables a esta discursividad totalizaron $31 \%$ de los casos. Finalmente, un 40,5\% fue catalogado como neutro o neutralizado ya que, o bien presentó ambos índices neutralizados, por adherir en cada índice a las dos frases (22 \%) o por rechazar las dos (6 \%), o bien manifestó en un índice una respuesta tecnologizante y en el otro una respuesta crítica (13\%).

Del cruce de estos tres valores en los dos ejes, obtuvimos nueve tipos de respuestas a las 12 frases, cuya distribución se encuentra reproducida en la Tabla 8. Observamos, en primer lugar, un predominio de los liberal-conservadores y tecnologizantes (tipo 9), o al menos con posiciones neutras en el eje tecnologizante (tipo 6). Estos dos tipos suman el $40 \%$ de los entrevistados. En cambio, los agraristas y al mismo tiempo críticos del discurso tecnologizante (tipo 1) son muy pocos (5\%).

En segundo lugar, como se puede ver en la misma tabla, existe una baja relación entre ambos ejes: los casos no se concentran en la diagonal descendente (\). En cambio, muchos agraristas (alrededor de un cuarto de ellos) tenían posiciones favorables al discurso tecnologizante (tipo 7), o varios liberales (casi un cuarto de los mismos) eran críticos del discurso tecnologizante (tipo 3). Por lo tanto, hemos confirmado la utilidad de analizarlos como dos ejes independientes.

Si analizamos más detenidamente las respuestas concretas que dieron a cada una de las 14 frases (descriptas a partir de sus valores medios, según la escalación de las respuestas $\underline{23}$ ), los agraristas y críticos del discurso tecnologizante (tipo 1) fueron los entrevistados que manifestaron más coherencia en sus respuestas. Como se observa en la Tabla 2 del Anexo, se destacaron por sostener respuestas distantes de la media en la gran mayoría de las frases (la segunda línea indica la distancia de los valores medios de cada grupo en relación a la media del total de casos, medida en desvíos estándar). En los casos en que no rechazan algunas frases liberales o tecnologizantes, lo hacen justamente porque las mismas tienen mucho consenso; podríamos decir que forman parte casi del sentido común de los productores (por ejemplo, la frase de que el derecho de la propiedad es sagrado, o que solo los productores deben decidir sobre su tierra).

En la posición opuesta, también fueron bastante coherentes las respuestas de los liberal-conservadores y tecnologizantes (tipo 9): altos valores en todas las frases de esas discursividades y bajos en las agraristas y críticas a las tecnologías. Si no fueron tan bajas las respuestas a la necesidad de leyes que frenen la concentración, de igual modo están claramente por debajo de la media.

Un tipo de sujetos curiosos son los agraristas y tecnologizantes (tipo 7). Ellos presentan el valor medio más bajo frente a la frase de defensa del derecho de propiedad de la tierra, un claro rechazo a la desregulación de los mercados y, coherentemente, están a favor de la intervención estatal que frene la concentración y que regule algunos mercados, pero, al mismo tiempo, piensan que las tecnologías beneficiaron a todos y no perjudicaron a los pequeños. 
Otro tipo relativamente extraño son los liberal-conservadores pero críticos del discurso tecnologizante (tipo 3). Adhirieron a todas las frases liberales y rechazaron todas las agraristas (con excepción del tema de las retenciones redistribuidas), pero, a su vez, eran críticos de las nuevas tecnologías y señalaban que habían afectado negativamente a muchos pequeños productores, al tiempo que pensaban que los verdaderos productores eran los que trabajan en el campo y que no era cierto que los productores ya no fuesen chacareros.

Luego podemos mencionar cuatro posiciones que se destacan por ser coherentes en uno de los ejes, pero tener posiciones "neutras" (o contradictorias) en el otro: agraristas o liberales sin posiciones claras en cuanto a lo tecnológico (tipos 4 y 6, respectivamente), y críticos de las tecnologías o tecnologizantes con posiciones neutras en cuanto al eje liberal-agrarista (tipos 2 y 8, respectivamente).

Por último, encontramos a aquellos que no tuvieron posiciones claras en ninguno de los dos ejes (tipo 5). En su gran mayoría respondieron mucho más positivamente a todas las frases que el conjunto.

\section{Vinculación entre respuestas a preguntas abiertas y a las frases}

Cabría esperar que esta diferenciación de los entrevistados según sus posiciones consolidadas en las 12 frases se asociara a sus respuestas a las preguntas abiertas, sin embargo, asombrosamente la relación ha sido bastante débil.

Como es posible observar en la Tabla 9 , en el caso de las palabras con que vinculaban a los pools de siembra, al concitarse un rechazo generalizado a estas empresas, prácticamente no hubo relaciones con los patrones de respuesta frente a las 12 frases de las discursividades públicas. Únicamente, los liberales y tecnologizantes (tipo 9) tuvieron un poco más de respuestas positivas o algo positivas, que sumaron un poco más del $20 \%$.

En la Tabla 10 se observa que tampoco hubo una relación clara entre las palabras asociadas con Monsanto y los posicionamientos ideológicos en las frases. Así, si bien la gran mayoría de los agraristas y los críticos tecnológicos asociaron a esta empresa con palabras críticas o incluso muy duras (tipos 1, 2 y 4), también entre un cuarto y algo más de un tercio de estos entrevistados la vincularon con palabras positivas. En forma inversa, entre los liberales y los tecnologizantes predominaron los términos positivos, pero también hubo un importante porcentaje de asociaciones muy críticas o, al menos, bastante críticas (Tipos 6, 8 y 9).

En relación con las respuestas frente a la frase La tierra para el que la trabaja, en la Tabla 11 se observa que, a pesar de cierta relación positiva entre el acuerdo y el agrarismo, alrededor de un quinto de los agraristas rechaza la frase, y que otro tanto de los liberales acuerda con la misma.

La respuesta a la pregunta acerca de cómo diferenciar a los productores agropecuarios no presentó ninguna relación interesante con los tipos ideológicos construidos a partir de las frases.

En síntesis, se confirma una muy baja o casi nula relación entre las posiciones ideológicas y las respuestas a las preguntas abiertas. Hemos interpretado este fenómeno en términos de que en las contestaciones a estas últimas emergería más el sentido común y, en particular, el "buen sentido" que nace de la práctica social (que llevaba, por ejemplo, a rechazar los pools, independientemente de los posicionamientos frente a las frases de las discursividades), y no tanto la adhesión a determinadas miradas ideológicas un poco más estructuradas.

\section{Ideología y conducta}

Hemos analizado el vínculo entre dos conductas políticas (la participación en acciones directas y el voto) y la ideología (según las respuestas a las preguntas abiertas y los posicionamientos ideológicos). En cuanto a las acciones directas, consideramos, en primer lugar, la participación en el conflicto del 2008 entre el gobierno y 
las patronales agropecuarias en torno a la resolución 125 que establecía las retenciones móviles a las exportaciones agrícolas. En segundo lugar, incluimos la conducta electoral según la elección a diputados nacionales de 2009 (cuando tuvo mucha incidencia el conflicto que había tenido lugar un año antes) y la elección presidencial de 2011.

En relación con el conflicto de 2008, del total de entrevistados, un 62 \% manifestó haber participado de los cortes de ruta y un 30 \% haber asistido, al menos, a uno de los actos de realizados en Rosario o en Palermo. Los posicionamientos ideológicos que surgen del acuerdo con las 12 frases parecen haber incidido sobre las conductas durante el conflicto, especialmente en el caso del eje liberal-conservador / agrarista. Así, los agraristas participaron mucho menos en los cortes de ruta (32\%), mientras que los liberal-conservadores tuvieron una actividad mucho más intensa (71 \%). Los “neutros” en este eje tuvieron una participación alta, aunque un poco menor (59 \%). En similar sentido, solo un $13 \%$ de los agraristas asistieron cuanto menos a uno de los actos, al igual que un $40 \%$ de los liberal-conservadores, y un $19 \%$ de los "neutros".

En cambio, no hubo tantas diferencias en la participación en el conflicto de 2008 según la discriminación en el eje tecnológico: los críticos participaron en un $66 \%$ y los tecnologizantes en un $61 \%$. De modo similar, la asistencia a los actos no fue muy diferente: $26 \%$ y $35 \%$, respectivamente.

Tampoco hemos podido encontrar relaciones claras entre las respuestas a las cuatro preguntas abiertas y la participación de los entrevistados durante el conflicto de 2008. Entre los entrevistados agrupados según sus asociaciones con las palabras pools de siembra o Monsanto, o según sus respuestas al pedido de clasificación de los productores o a la frase La tierra para el que la trabaja, las diferencias en su participación en el conflicto siempre fueron menores a un $10 \%$.

De igual modo, no hubo asociación entre las respuestas a las preguntas abiertas y el voto en 2009 o en 2011. En cambio, sí fue posible observar relaciones entre la conducta electoral y los posicionamientos ideológicos en las 12 frases, en particular con el eje liberal/agrarista. Tal como puede observarse en la Tabla 12, en el voto a diputados de 2009 (a un año del conflicto sobre las retenciones móviles), los liberal-conservadores votaron a De Narváez un 24 \% más que los agraristas (43\% versus $20 \%$ ), mientras que éstos lo hicieron por Néstor Kirchner con un diferencial de similar magnitud, en relación con los liberales (29 \% versus 5 \%). Por el contrario, el eje tecnologizante/crítico tecnológico no muestra relación con este voto. Merece destacarse la gran inclinación por Margarita Stolbizer, que se impuso a lo largo de todos los tipos en ambos ejes, sin que se puedan señalar diferencias.

En el caso de las elecciones presidenciales de 2011, también encontramos una relación con los posicionamientos en el eje liberal/agrarista. Como se observa en la Tabla 13, hubo un diferencial entre agraristas y liberales en el caso del voto a Cristina Fernández de Kirchner del 35 \% (36 \% versus 1 \%), y en el caso del voto a Binner en un $11 \%$ (43\% versus $32 \%$ ). A la inversa, en el caso de los liberales, el incremento en favor de Alfonsín es del 20 \% (29 \% versus 9 \%), y de Duhalde del 13 \% (15\% versus 2 \%). Nuevamente, no surgieron relaciones entre este voto y las posiciones en el eje tecnologizante/crítico tecnológico.

\section{Relación de la ideología con las características etáreas, educativas, de residencia y la tenencia del suelo o el tamaño de la unidad productiva}

Hemos analizado la posible incidencia de una serie de variables sobre las posiciones ideológicas y las respuestas a las preguntas abiertas. Se consideraron la edad de los entrevistados, el tamaño de sus explotaciones, la forma de tenencia del suelo (computada como porcentaje de la superficie total de la explotación que el entrevistado tenía en propiedad), el lugar de residencia (si vivía o no en el campo, y en caso de residencia parcial, se computó la cantidad de días que vivía allí), y el mayor nivel educativo que 
había alcanzado. En líneas generales podemos decir que no se encontraron relaciones fuertes entre estas variables y las respuestas de los entrevistados, en el sentido de que sus características estuvieran asociadas claramente a un tipo de contestación. Solamente hemos podido observar ciertos incrementos o descensos en los porcentajes, sin modificarse el predominio de la respuesta que era mayoritaria en el total de los casos.

En relación con las posiciones ideológicas que surgen de las 12 frases en el eje liberal/agrarista, la variable que parece haber incidido en mayor grado es el tamaño de las explotaciones. Los productores con unidades de hasta 50 hectáreas eran quienes presentaban un mayor porcentaje de agraristas (19\%), mientras que era en este estrato donde los liberal-conservadores tenían un menor peso, aunque de todos modos eran más que los agraristas (29 \%). En cambio, por encima de las 500 hectáreas eran muy pocos los agraristas (7 \%) y predominaban claramente los liberales (65\%).

También pesaba levemente la residencia en el campo: los que vivían en el campo eran en un 20 \% agraristas, mientras que los que no residían allí lo eran en un $13 \%$ (de todos modos predominaban los que tenían ideas liberal-conservadoras, sumando en ambos casos el $52 \%$ de los entrevistados).

No encontramos ninguna incidencia del resto de las variables sobre el eje liberal/agrarista. Las diferencias en los valores de este eje según los grupos de edad, la tenencia del suelo o el nivel educativo fueron sumamente pequeñas.

En relación con el eje tecnologizante/crítico tecnológico, no pudieron detectarse vínculos claros con las variables independientes consideradas. Solo fue posible observar pequeñas diferencias en algunas variables. En el caso de la residencia, se encontró que un 25 \% de los que vivían en el campo era tecnologizante, mientras que lo era un $35 \%$ de quienes no residían en la explotación. En cuanto al tamaño, entre los productores con unidades de muy pequeño tamaño (menores a 50 hectáreas) solo el $16 \%$ era tecnologizante, mientras que lo era el 32 \% de quienes tenían más de 50 hectáreas. Y en el caso del nivel educativo, entre los que no habían llegado más que hasta la secundaria incompleta, el $36 \%$ era crítico tecnológico y el $20 \%$ tecnologizante, mientras que entre quienes al menos habían terminado la secundaria, el $25 \%$ era crítico y el $35 \%$ era tecnologizante. No fue posible observar ninguna relación con el eje tecnologizante/crítico tecnológico, en los casos de la tenencia del suelo o la edad.

En cuanto a las preguntas abiertas, la incidencia de estas variables independientes parece haber sido muy baja. Para el caso de las palabras que se vincularon con pools de siembra, solo es posible mencionar una leve relación con la edad: aunque todos los grupos etarios eran predominantemente críticos, en el caso de los mayores de 40 años alrededor de un $10 \%$ de los entrevistados tuvo frases positivas, mientras que entre quienes eran menores a esa edad prácticamente ninguno las tuvo.

En cuanto a las palabras asociadas con Monsanto, solo la residencia y el tamaño de las unidades tuvieron alguna incidencia. Entre quienes vivían en el campo, el 28 \% calificó a esa empresa de forma muy negativa, y el $30 \%$ de forma positiva, mientras que quienes no residían en el campo lo hicieron en un $21 \%$ y un 37 \%, respectivamente. En cuanto al tamaño, los productores con menos de 200 hectáreas dieron descripciones muy negativas en un $31 \%$ y positivas en un $33 \%$, mientras que los de más de 1.000 hectáreas lo hicieron en un $9 \%$ y un $60 \%$, respectivamente. El estrato de 200 a 1.000 hectáreas fue muy crítico en un $23 \%$ de los casos y positivo en un $33 \%$.

Las distintas formas de clasificar a los productores rurales no parecen tener casi relación con las variables consideradas.

Por último, las respuestas a la frase La tierra para el que la trabaja solo se relacionaron con el tamaño, la residencia y la edad. Los productores con unidades más pequeñas la apoyaron en un mayor porcentaje: 36 \% de los de menos de 50 hectáreas y 32 \% de los de 50 a 200 hectáreas, mientras que 12 \% de los de más de 
500 hectáreas. Mientras que el rechazo se incrementó al aumentar la escala: 9 \% de los de menos de 50 hectáreas, 29 \% de los de 50 a 200, y 41 \% de los de más de 500 hectáreas.

Entre los que vivían en la explotación, un 33 \% acordaba con la frase y un 25 \% la rechazaba. En cambio, los porcentajes eran de un $22 \%$ y un $32 \%$ entre quienes no residían en el campo.

Y en el caso del nivel educativo, un $34 \%$ de los que solo habían alcanzado hasta la secundaria incompleta acordaban con que la tierra debía ser para quien la trabajara y rechazaban la idea un $20 \%$, pero entre quienes al menos habían finalizado el secundario, solo un $19 \%$ acordaba con esta frase, y un 38 \% la rechazaba.

\section{Identificación con los intereses de distintos tipos de productores agropecuarios: el sentido de separación}

Por último, ante el pedido de que los entrevistados dijeran cuán parecidos creían que eran sus intereses en relación con los intereses de distintos tipos de productores, en líneas generales, encontramos una mayor identificación con los intereses de un “dueño de 200 hectáreas y que toma en arriendo 100” (45 \% considera que tienen iguales intereses), seguidos por el "pequeño chacarero que arrienda unas 100 hectáreas” (36 \%) y el "productor agropecuario dueño de 500 y que toma en arriendo otras 500" (31\%), tal como se observa en la Tabla 14. Mucho menores fueron las identificaciones con "un gran estanciero, con 5.000 hectáreas y 5.000 vacunos" (8 \%) y "un campesino de Santiago del Estero que no tiene título de propiedad y lucha por la tierra" (8 \%). Sintomáticamente, en último lugar, quedó la identificación de intereses con un "gran pool de siembra, que organiza la agricultura en 50.000 hectáreas" (solo un $2 \%$ manifestó que tenía los mismos intereses que ellos).

Sin embargo, este análisis global poco nos dice acerca de cuánto los productores de cada estrato de tamaño vinculan sus intereses a los de su propio grupo, o si tienen una visión más difusa en la que no diferencian demasiado sus intereses de los de los productores de otras escalas. Por eso, realizamos un análisis particular en cada estrato de tamaño y aplicamos un análisis de clusters para cada una de las escalas.

En este análisis por estrato, pudimos diferenciar dos tipos de clusters de entrevistados. Por un lado, aquellos grupos que consideraban que solo tenían sus mismos intereses quienes poseían unidades de un tamaño relativamente similar al suyo (en general, del mismo estrato o de un estrato por encima y/o de uno por debajo); en estos casos decimos que presentaban un "sentido de separación”. Por otro lado, estaban aquellos grupos que consideraban que casi todos los productores tenían sus mismos intereses (aunque en muchos casos dejaban fuera los pools de siembra o a los campesinos santiagueños). En estos casos, no habría "sentido de separación”.

Como se observa en la Tabla 15, hay un claro sentido de separación en un 70 \% de los entrevistados. Además, existe cierta relación entre el tamaño de la unidad productiva y el sentido de separación: entre los pequeños productores hay un mayor sentido de separación, mientras que entre los mayores, es mucho menor.

Esta tabla, en realidad, es el resultado de la agregación de todos los análisis de clusters que efectuamos en los distintos estratos de tamaño. En el estrato de menos de 50 hectáreas, el cluster más grande indica identificación de intereses con los pequeños arrendatarios y con los de 300 hectáreas; otro cluster incluye a estos dos actores y al campesino, mientras que un cluster con menos cantidad de entrevistados plantea que comparte los intereses con todos los tipos de productores, incluso con los de mayor tamaño (este cluster claramente no presenta sentido de separación). En el estrato de productores de 50 a 200 hectáreas, identificamos dos clusters: uno que no diferenciaba y otro que solo presentaba asociación de intereses con los pequeños arrendatarios y los productores de 300 hectáreas. En el estrato de 200 a 500 se agruparon cinco clusters. En dos de ellos se identifican con los productores de 300 hectáreas (en uno, solo con ellos y en otro, además, con los de arrendatarios de 100 hectáreas). En cambio en los otros tres clusters la identificación va 
desde los estancieros hasta los campesinos, o los pequeños arrendatarios (en uno de los clustersincluyen aun a los pools). En el estrato de 500 a 1.000 hectáreas se formaron dos clusters. En uno, con sentido de separación, solo se consideraron con iguales intereses principalmente a los productores de 1.000 hectáreas y a los de 300 hectáreas, mientras que en los dos restantes se consideraron con iguales intereses a casi todos los productores (excepto los pools). En el estrato de más de 1.000 hectáreas (en el cual se consideraron en forma conjunta el estrato de 1.000 a 2.000 hectáreas y el de más de 2.000 por la poca cantidad de casos de este último) se identificaron dos clusters. En uno, la identificación fue solo con el productor de 1.000 hectáreas, mientras que en el otro se amplió desde el arrendatario de 100 hectáreas hasta el estanciero de 5.000 (aunque no se identificó con el pool de siembra).

Además de estas diferencias en la conciencia de un sentido de separación según el tamaño de las unidades, no encontramos incidencia de la edad o el nivel educativo del entrevistado. En cambio, sí encontramos asociaciones con la tenencia del suelo y el lugar de residencia. Entre los propietarios fue mucho más habitual el sentido de separación (76 \% de los dueños de campos lo presentaban) que entre los que no poseían tierras en propiedad (solo el $53 \%$ lo manifestó). Tal vez, en este último caso, una estrategia de expansión o retracción de la superficie trabajada según las condiciones y oportunidades de los mercados, podría estar generando una menor identificación con los intereses de tipos más precisos de productores.

En cuanto al lugar de residencia, el 78 \% de los que vivían en su unidad productiva tenían un sentido de separación, mientras que solo lo manifestaron un 62 \% de quienes no residían en el campo.

Por último, podemos afirmar que, en líneas generales, no hay una clara relación entre un mayor o menor sentido de separación y las posiciones ideológicas en el eje liberalismo/agrarismo: los tres agrupamientos (liberal-conservadores, neutros y agraristas) presentaban un 68 \% de entrevistados con sentido de separación. Sin embargo, si se realiza el análisis por escalas de tamaño es posible descubrir que, por encima de las 1.000 hectáreas, tienen más sentido de separación aquellos con una ideología más liberal-conservadora (tal vez más conscientes de sus intereses).

En cuanto al eje tecnologizante, ha sido posible detectar un mayor sentido de separación de aquellos que son críticos de las tecnologías (85 \% de sentido de separación) que entre los que adhieren al discurso tecnologizante, aunque de todos modos entre estos últimos también predominaba el sentido de separación (65\%).

\section{Algunas conclusiones sobre la ideología de los productores bonaereneses}

El resultado más notorio que surge del análisis de la encuesta es el hecho de que la enorme mayoría de los entrevistados no tiene una ideología mínimamente estructurada y relativamente coherente desde la que pueda dar cuenta de la realidad agraria. Cuando consideramos las preguntas en forma conjunta, son extremadamente pocos aquellos que mostraron sistematicidad en las respuestas.

Lo más llamativo es que los mismos entrevistados adherían a frases de discursividades contrapuestas. En este sentido, por la presencia de bajas correlaciones entre las respuestas a las frases de una misma orientación ideológica, y por la inexistencia de claras relaciones negativas entre las respuestas a frases de discursividades opuestas, resultó extremadamente difícil agrupar las variables en factores que las resumieran: los análisis de componentes principales o el análisis factorial arrojaron resultados de nula utilidad. Tampoco fue sencillo reunir a los entrevistados en tipos que se comportaran de formas similares. Así, el análisis de clusters, que buscaba construir agrupamientos de productores sin siquiera la necesidad de presupuestos ideológicos claros, tampoco arrojó grupos con características lo suficientemente nítidas como para lograr interpretaciones fructíferas. Estos diferentes análisis confirmaron la primera conclusión que ya hemos comentado: la poca consistencia ideológico-doctrinaria de los productores rurales bonaerenses. 
Una aproximación más detenida -que admite niveles de imprecisión doctrinal más altos- permitió diferenciar a los productores según sus respuestas a las frases, consideradas en pares, para que de este modo se pudiera distinguir entre los que tenían mayor o menor coherencia en cada par. Así, se construyeron ocho índices que se agruparon, a su vez, en dos ejes: liberal-conservador / agrarista; tecnologizante / crítico de las tecnologías. En el primero de estos ejes se visualizó un claro predominio de los valores liberalconservadores, con un $54 \%$ de los entrevistados que adherían a una mayoría de frases típicas de esta discursividad, al tiempo que rechazaban, al menos, la mayoría de las frases agraristas. Por otro lado, solo un 14 \% se ubicó en valores predominantemente agraristas (y, al mismo tiempo, renegó de las frases liberalconservadoras). Un 32 \% manifestó posiciones neutras o neutralizadas por adherir a frases agraristas y liberales, o por rechazar ambas.

En cambio, en el otro eje, las posiciones estuvieron más equilibradas: $31 \%$ con respuestas predominantemente tecnologizantes, $29 \%$ con respuestas mayoritariamente críticas a las tecnologías o a los agronegocios, y un $40 \%$ con posiciones neutrales.

La combinación entre ambos ejes diferenció nueve posiciones ideológicas, en las que se destacan por su importancia los liberales y tecnologizantes (22\%), los liberales y neutros en lo tecnológico (19 \%), los liberales y críticos tecnológicos (13 \%) y los que tuvieron posiciones neutras o neutralizadas en ambos ejes (15\%).

Así, la segunda conclusión a la que hemos arribado remite al predominio de una discursividad liberalconservadora, aunque no sistemáticamente estructurada. Una preponderancia que indica la fuerte eficacia interpelativa de algunas frases liberal-conservadoras que son estructuradoras de una mirada global del mundo agrario más atenta a considerar el derecho de propiedad como algo sagrado, y a sostener que solo los productores deben decidir qué y cómo se produce en su tierra (89 \% y 76 \% de acuerdo total, respectivamente). Recordemos que muy pocos estaban solo un poco o nada de acuerdo con estas frases; incluso la mayoría de los que en el conjunto de las frases presentó un perfil “agrarista”, acordó con estas dos frases. Por ende, se confirmaría el éxito de la retórica del mercado que, según Jameson, ha sido un componente central de la lucha ideológica por legitimar o deslegitimar el discurso de la izquierda (Jameson, 2003, p. 312).

Sin embargo, esta eficacia interpelativa del liberalismo-conservador no lograba anular la adhesión a ciertas frases del discurso agrarista. Por ejemplo, la idea de que son necesarias leyes que frenen la concentración logró un 79 \% de respuestas total o medianamente de acuerdo, destacándose que incluso lo hacían un 60 \% de los que clasificamos como liberales. En similar sentido, la frase que propone mantener las retenciones pero para darles créditos a los productores familiares obtuvo un $70 \%$ de acuerdo total o mediano, y una adhesión de alrededor de la mitad de los liberal-conservadores. Sintomáticamente, estas frases no incorporan el término Estado en su enunciación. En cambio, las frases agraristas que propugnan explícitamente la intervención del Estado para regular los mercados de tierra, el uso del suelo, y la comercialización de carnes y granos tuvieron niveles de adhesión mucho menores. Y, en estos casos, los que agrupamos como liberalconservadores, en su enorme mayoría, rechazaron estas frases.

Del análisis de las respuestas a las frases agraristas podemos extraer, como tercera conclusión, que la adhesión general a una discursividad liberal-conservadora por parte de la mayoría de los entrevistados, no significó un rechazo sistemático de toda idea agrarista, sino a la propuesta de la intervención estatal en los distintos mercados.

Y -también del análisis de las frases agrarias- como cuarta conclusión, podemos afirmar que los que manifestaron una adhesión al discurso agrarista fueron solo alrededor de un sexto de los entrevistados y que, incluso en estos casos, consensuaban varias frases liberal-conservadoras. 
Una quinta conclusión es que el discurso del agronegocio o de celebración del avance tecnológico, como superador de las antiguas tensiones agrarias, no ha logrado la misma hegemonía que el liberalismo, ya que los posicionamientos de los entrevistados fueron bastante equilibrados entre la adhesión a esta discursividad y a la de las interpelaciones críticas de la misma.

La sexta conclusión es que este discurso tecnologizante, en general, se articula con las posiciones liberalconservadoras, aunque sin llegar a una asociación demasiado fuerte (son dos ejes ideológicos diferenciados).

Del análisis de las respuestas a las preguntas abiertas encontramos una disociación entre ellas y los posicionamientos ideológicos que surgen del análisis de las frases de las distintas discursividades. Así, casi todos los entrevistados tuvieron una mirada muy crítica de los pools de siembra, independientemente de sus posicionamientos ideológicos. De modo similar, un importante porcentaje diferenció a los productores según el tamaño de sus explotaciones o su trabajo directo en el establecimiento, una conceptualización más acorde con una perspectiva agrarista, aunque muy pocos habían manifestado posiciones agraristas en términos doctrinales. Algo parecido ocurrió con la solicitud de palabras asociables a Monsanto, que no presentó una relación clara con el posicionamiento dentro del eje tecnologizante/crítico tecnológico.

Llamativamente, la frase la tierra para el que la trabaja, a pesar de ser un enunciado "clásico" de la discursividad agrarista y de connotaciones políticas muy fuertes, mantuvo cierto nivel de vigencia o, mejor dicho, presentó un bajo nivel de rechazo explícito (un tercio de los entrevistados). No es que todos adhirieran a políticas de reforma agraria, sino que la mayoría de los que no rechazaron la frase solo acordaron parcialmente con la misma: la consideraron correcta pero utópica o, sobre todo, la resignificaron en términos de que no debería haber campos improductivos.

Por último, la identificación de intereses compartidos con distintos tipos de sujetos agrarios ha mostrado la presencia de un claro sentido de separación en un $70 \%$ de los entrevistados. Y este sentimiento no está determinado por los posicionamientos ideológicos (más allá de algunas relaciones que hemos comentado en el correspondiente apartado).

Para finalizar queríamos formular algunas interpretaciones más específicas. En primer lugar, que estas disociaciones entre preguntas abiertas e identificación de intereses, y también entre los tipos ideológicos que surgen del análisis de las frases confirman la primera conclusión: la inexistencia de sólidas posiciones ideológicas que estructuren el conjunto de las respuestas.

En segundo lugar, hemos interpretado esta baja relación entre los posicionamientos ideológicos y las contestaciones a las preguntas abiertas y a la identificación de intereses, en términos de que en estas últimas emergería más el sentido común y, en particular, el "buen sentido" que nace de la práctica social, y no tanto la adhesión a determinadas miradas ideológicas estructuradas. Esta podría ser una séptima conclusión: la confirmación del peso del "buen sentido" en algunas cuestiones, que se sobrepone a las hegemonías ideológicas. Así, por ejemplo, un productor podía manifestar cierta inclinación ideológica hacia el liberalismo-conservador o hacia el discurso de los agronegocios, y sin embargo, este posicionamiento ideológico no lo conducía a opinar positivamente sobre los pools de siembra o sobre Monsanto, ni tampoco a considerar que sus intereses eran los mismos que los de un gran estanciero.

Cabe aclarar que hemos descartado que esta inconsistencia entre respuestas a preguntas cerradas y abiertas surgiese de una falta de validez en la metodología de registro de los posicionamientos frente a las discursividades a través de la manifestación de grados de acuerdo o desacuerdo con sus frases típicas. Llegamos a esta apreciación a partir de relacionar ambas clases de preguntas con las conductas de los entrevistados. Este análisis lo efectuamos con las acciones de los entrevistados durante el conflicto del 2008 y con sus opciones electorales en las votaciones de 2009 y 2011. Encontramos mucha mayor vinculación entre estas conductas y los tipos ideológicos que emergen de las respuestas a las frases, que el vínculo que 
encontramos con las contestaciones a las preguntas abiertas (que no presentaban casi ninguna relación con los comportamientos). Podemos concluir que los posicionamientos frente a las frases estarían revelando una base ideológica de mayor incidencia en la personalidad que las respuestas a las preguntas abiertas; aunque, como ya hemos dicho, esta base ideológica está poco estructurada en términos doctrinales.

Como última conclusión de este artículo, queremos destacar que no fue posible observar incidencias fuertes de las características de los encuestados sobre sus posiciones ideológicas registradas tanto con las preguntas abiertas como con los acuerdos con las frases. Ni las diferencias en la edad, el nivel educativo, el tamaño de las explotaciones, la forma de tenencia del suelo o el lugar de residencia determinaron un cambio en el tipo de respuesta mayoritaria. Solo pudieron detectarse algunos incrementos en los porcentajes para el caso de determinados grupos de entrevistados, discriminados según estas variables.

Hasta aquí el análisis con el que contamos hasta el presente. Resta continuar con el proceso de codificación de un importante número de preguntas abiertas, algunas de las cuales permitirán completar la descripción de los posicionamientos ideológicos de los entrevistados, y otras aportarán a la caracterización de otros aspectos de sus vidas. La incorporación de estas variables al conjunto del análisis podrá, tal vez, aportar nuevas perspectivas a las conclusiones parciales que acabamos de presentar.

\section{Notas}

1 Esta encuesta fue realizada en el marco de nuestro proyecto de investigación "Modelos agrarios en tensión” de la UNQ, en forma conjunta con el Proyecto de Investigación Plurianual del CONICET “Actores sociales, Estado y política en el agro pampeano, 1930-2008”, radicado en la UNLP.

2 Como lo ha señalado Halperín Donghi (1982: 120-138), muchos de los políticos e intelectuales liberales de la segunda mitad del siglo XIX se habían manifestado en favor de la pequeña y mediana propiedad. De todos modos, finalmente las medidas estatales tomadas promovieron la creación de enormes latifundios. Luego, la extraordinaria expansión de la ganadería y la agricultura sirvieron para consolidar una hegemonía favorable al mantenimiento de la situación constituida, sin mayores necesidades de una argumentación. Sospechamos que el motivo de este silencio, tal vez, fuese doctrinal: siempre le fue difícil al liberalismo sostener discursivamente el derecho a la apropiación privada de la tierra en enormes latifundios y la no intervención estatal a favor del acceso a la propiedad por parte de los pequeños o medianos agricultores.

$\underline{3}$ Reservamos el concepto de formación discursiva para dar cuenta de la base objetual común de un conjunto de discursos. Y dentro de esta idea de base objetual, para nosotros, se encontrarían los objetos y lo que denominamos las conceptualizaciones objetuales (Balsa, en prensa). Retomando a Foucault en La arqueología del saber, podemos decir que una formación discursiva constituye un a priori histórico, en tanto forma de positividad que "define un campo en el que pueden eventualmente desplegarse identidades formales, continuidades temáticas, traslaciones de conceptos, juegos polémicos” (Foucault, 1969, p. 215). Este a priori sería condición de realidad para los enunciados, cuestión que fue desarrollada primero en Las palabras y las cosas (Foucault, 1985).

4 Sobre esta ideología y su conformación gremial y política en las décadas de 1940 a 1980, ver Lattuada (1987).

$\underline{5}$ En esta línea, Zizek plantea que "cuando se denuncia un procedimiento como 'ideológico por excelencia', podemos estar seguros de que su inversión no es menos ideológica” y, además, como lo señalaba Ducrot, "no se puede trazar una clara línea de separación entre los niveles descriptivo y argumentativo del lenguaje” (Zizek, 2003, p. 10 y p. 19). 
6 Sobre la construcción del conflicto de 2008, por parte de los tres principales diarios nacionales, puede consultarse Cremonte (2010).

7 De hecho, el principal hallazgo de la investigación de Fromm sobre los obreros y empleados alemanes hacia 1929 fue que sus opiniones manifiestas predominantemente de izquierda, podían ser neutralizadas o pervertidas por rasgos de personalidad más profundos muy proclives a la aceptación de actitudes autoritarias (Fromm, 1939/2012). En una línea similar, el estudio dirigido por Adorno en los Estados Unidos de posguerra buscaba hallar rasgos autoritarios que podían favorecer la aceptación de propuestas fascistas o antisemitas no visibles en forma directa (Adorno et al., 1965).

$\underline{8}$ En el trabajo de Brussino et al. (2011), por ejemplo, se interrogó a los entrevistados y entrevistadas sobre la base de 48 ítems sobre diversas cuestiones (política social, economía, sexualidad, drogas, religión, seguridad, comunicación, medio ambiente y nacionalismo), siempre en función del eje intervención/no intervención del Estado en cada cuestión, a los que se podía responder en una escala de cinco puntos, entre nada de acuerdo y totalmente de acuerdo.

\section{9 Álvarez, Leavy y Marino (2009) y Mosciaro y Dimuro (2009).}

10 Se calculó el proceso de concentración que tuvo lugar entre 1988 y 2002 en el conjunto de la provincia de Buenos Aires para cada uno de los estratos de tamaño, y luego se estimó que en el período 2002-2013, cada estrato habría sufrido una reducción (o crecimiento en el caso de las de más de 1.200 ha) en el número de unidades de la mitad de la magnitud del que había tenido en el período intercensal. Somos conscientes de que es una estimación conservadora. Con el análisis de lo acontecido en cada zona, se realizó el recálculo de la cantidad de casos según este método de ajuste por concentración.

11 Para calcular las modificaciones en la cantidad de los diferentes tipos de explotaciones debidas al proceso de agriculturización se analizaron los cambios en la cantidad de superficie cultivada de todos los partidos que conforman cada zona. Luego se realizaron ajustes en las distribuciones relativas de cada zona, de modo de garantizar el incremento del número de explotaciones agrícolas o agrícola/ganaderas que, en general, hubo debido al aumento en la superficie agrícola.

$\underline{12}$ En el texto hemos usado el masculino para referirnos al conjunto de los entrevistados y las entrevistadas. A pesar de que habitualmente no hacemos esta simplificación pues invisibiliza a las mujeres, en este caso efectuamos esta generalización, porque la enorme mayoría eran hombres, y para simplificar la redacción.

$\underline{13}$ Puede consultarse el análisis de esta encuesta en Balsa (2008).

14 Acerca del uso del pretest cognitivo, hemos atendido especialmente las recomendaciones de Fowler (1995) y Tourangeau, Rips y Rasinski (2004).

$\underline{15}$ La formulación era la siguiente: “Ahora quisiera su opinión sobre algunos temas. Para ello le voy a pedir que me diga brevemente qué piensa en relación con una palabra que yo le diré. No es necesario que la piense mucho, sino que me diga la primera frase que le venga a la mente. Por ejemplo, si usted me dijera 'casa', yo diría 'a mí me encantaba la casa de mis padres', o 'estamos ahorrando para comprar una casa', y cosas así. Por ejemplo, si yo le digo 'retenciones’, usted ¿Qué frase me diría?”

16 Recordemos que el cuadrado del coeficiente de correlación, denominado coeficiente de determinación, indica el porcentaje de variabilidad de una variable que es explicado estadísticamente por la variabilidad de la otra variable. Así por ejemplo, un coeficiente de correlación de 0,33, implica un coeficiente de determinación de 0,109 , que puede interpretarse como que una variable "explica" solo el 10,9 \% de la variabilidad de la otra. 
17 Se destacan las relaciones entre la frase que pregona la mejor situación de los productores debido a las nuevas tecnologías, con la que indica que en el campo los más competitivos no son los más grandes sino los que mejor saben hacer, y entre la frase que señala que los productores ya no son chacareros sino empresarios con dos frases: la que indica que lo más importante es el conocimiento -más que el tamaño-, y la referida a la igualdad de intereses dentro de la cadena agroindustrial.

18 Ver detalles en la Tabla 1 del Anexo. Allí puede observarse que hay una correlación relativamente fuerte entre la frase referida a que el Estado debería volver a regular los mercados con juntas de granos y carnes, con la frase que explicita que el Estado debe regular el mercado de arrendamientos.

19 Recordemos, muy sintéticamente, que el análisis de componentes principales procura hallar o producir nuevas variables que logren reducir la cantidad de dimensiones de una matriz de datos, a partir de que estas nuevas variables (o “componentes principales”) logren capturar la mayor parte de la variabilidad total de los datos con un número sustancialmente menor de variables que las originales. El método de análisis factorial trabaja, en general, a partir de estos componentes y, considerándolos factores, procede a su rotación para lograr una mejor capacidad interpretativa dichos factores en relación con las variables originales (más detalles en Johnson y Wichern, 1998).

$\underline{20}$ El análisis de clusters procura la construcción de conglomerados o grupos, en este caso de entrevistados, según las mayores similitudes que presentasen en forma simultánea en el conjunto de las catorce variables. Esta metodología presenta una serie de variantes según las distintas técnicas de aglomeración, los cálculos de las distancias entre los grupos que se van formando y los métodos de cálculo de las distancias entre los casos (más detalles en Johnson y Wichern, 1998).

$\underline{21}$ En primer lugar, al 0,5\%, agregamos a quienes tuvieron una posición agrarista en cuatro índices y en los dos restantes manifestaron posiciones neutralizadas, y así sumamos un 5,3 \%, que se incrementó a un 10,5 \% al agregar los casos de tres posiciones agraristas y al menos una neutra y en los que hubo cuatro adhesiones al agrarismo y dos al liberalismo. Finalmente sumamos a quienes tuvieron cuatro posiciones neutralizadas, pero el resto agraristas, y se llegó a un $14 \%$.

$\underline{22}$ Para ello, en primer lugar incorporamos a quienes tuvieron posiciones claramente liberales en cuatro índices y neutras en los dos restantes; sumaron un 26,3\%. Agregamos los casos con tres índices con posiciones liberales y el resto con mayoría neutralizada, y alcanzamos el 37,5 \%. Además, sumamos a quienes tuvieron cuatro neutralizadas pero dos liberales, y llegamos a un 53,5 \%.

$\underline{23}$ Recordar que computamos 1 para cada respuesta Totalmente de acuerdo, 0.66 para Medianamente, 0,33 para Solo un poco y 0 para Nada.

\section{Bibliografía}

Adorno et al. (1965). La personalidad autoritaria. Buenos Aires: Editorial Proyección.

Althusser, L. (1970). Ideología y aparatos ideológicos del Estado. Freud y Lacan. Buenos Aires: Nueva Visión.

Álvarez, R., Leavy, S., y Marino, M. (2009). Zonas Agroeconómicas Homogéneas Buenos Aires Norte. Buenos Aires: INTA.

Balsa, J. (2006a). Las tres lógicas de la construcción de la hegemonía. Theomai, 14. Disponible en http://revista-theomai.unq.edu.ar/NUMERO14/ArtBalsa.pdf 
Balsa, J. (2006b). El Desvanecimiento del mundo chacarero. Transformaciones sociales en la agricultura bonaerense, 1937-1988. Bernal: Universidad Nacional de Quilmes Editorial. Disponible en http://iesac.unq.edu.ar/jbalsa

Balsa, J. (2007). Las disputas hegemónicas en torno a las cuestiones sociales agrarias de la pampa argentina en la actualidad. En N. Girbal y S.R. de Mendonça, Cuestiones agrarias en Argentina y Brasil (pp. 149-170). Buenos Aires: Prometeo Libros.

Balsa, J. (2008). La ideología de los productores rurales pampeanos y su análisis en términos de las disputas hegemónicas. Realidad Económica, 237, 55-79.

Balsa, J. (2010). La cuestión agraria y la emergencia del discurso tecnologizante: el posicionamiento de las entidades agropecuarias argentinas en los años cincuenta y sesenta. Trabajo presentado en el VIII Congreso Latinoamericano de Sociologia Rural, Porto de Galinhas, Brasil.

Balsa, J. (2012). Formaciones discursivas y disputas por la hegemonía en torno a los modelos de desarrollo agrario. En J. Balsa y S. Lázzaro Agro y política en Argentina, Tomo 1: El modelo agrario en cuestión, 19301943 (pp. 35-117). Buenos Aires: Ciccus. Disponible en: http://iesac.unq.edu.ar/jbalsa

Balsa, J. (2015). Las discursividades sobre la cuestión agraria durante el peronismo clásico. En O. Graciano y G. Olivera (coord), Agro y política en Argentina, Tomo II: Actores sociales, partidos políticos, $e$ intervención estatal durante el peronismo, 1943-1955 (pp. 19-92). Buenos Aires: Ciccus.

Balsa, J. (en prensa). Formaciones y estrategias discursivas, y su dinámica en la construcción de la hegemonía. Propuesta metodológica con una aplicación a las disputas por la cuestión agraria en la Argentina de 1920 a 1943. Papeles de Trabajo, IDAES - UNSAM.

Brussino et al. (2011). Dimensión operativa de la ideología política en ciudadanos de Córdoba - Argentina. Psicología Política, 43, 85-106.

Carniglia, E. (2011). Las ruralidades de la prensa. Agronegocio, tecnología y agrarismo. Río Cuarto: Universidad Nacional de Río Cuarto.

Córdoba, M. S. (2015). Viaje al corazón del negocio agrícola. Dispositivos de legitimación e intervención territorial del modelo de agronegocios en Argentina (Tesis doctoral). Universidad Nacional de San Martín (mimeo), Argentina.

Cremonte, J. P. (2010). Cada cual atiende su juego. La construcción del conflicto entre el Gobierno nacional y las entidades agropecuarias en Clarín, La Nación y Página/12. En R. Aronskind y G. Vommaro (comp.), Campos de batalla (pp. 227-265). Buenos Aires: UNGS-Prometeo.

Foucault, M. (1969). La arqueología del saber. Buenos Aires: Siglo XXI.

Foucault, M. (1985). Las palabras y las cosas. Buenos Aires: Planeta-Agostini.

Fowler, F. J. Jr (1995). Improving Survey Questions. Thousand Oaks: Sage.

Fromm, E. ([1939] 2012). Obreros y empleados en vísperas del Tercer Reich. Un análisis psicológico-social. Buenos Aires: Fondo de Cultura Económica.

Fromm, E., y Maccoby, M. ([1979] 1992). Sociopsicoanálisis del campesino mexicano. México: Fondo de Cultura Económica.

Gálvez Vera, J. L., y Terceros Pavisich, S. X. (2009). El nuevo mapa político boliviano. En M. Braun y C. Straw (comp.), Opinión pública: una mirada desde America Latina (pp. 53-69). Buenos Aires: Emecé Editores. 
Guerring, J. (1997). Ideology: A definitional analisis, Political Research Quarterly, 50(4), 957-994.

Gramsci, A. (1986). Cuadernos de la Cárcel. Tomo 4. México: Editorial Era.

Gramsci, A. (2000). Cuadernos de la Cárcel. Tomo 6. México: Editorial Era.

Gras, C. (2007). Apuntes sobre la construcción identitaria de un nuevo empresariado en el agro argentino. Trabajo presentado en las V Jornadas Interdisciplinarias de Estudios Agrarios y Agroindustriales, Buenos Aires, Argentina.

Hall, S. (2003). Introducción: ¿quién necesita 'identidad’? En S. Hall y P. du Gay (comp.), Cuestiones de identidad cultural. Buenos Aires: Amorrortu editores.

Halperín Donghi, T. (1982). Una nación para el desierto argentino. Buenos Aires: CEAL.

Hernández, V. (2013). Genealogía de una elite rural: elucidación antropológica de una práctica de poder. Mundo Agrario, 13(26).

Ibarómetro, consultora (2015). Radiografía ideológica de los argentinos. Encuesta nacional. Recuperado de http://www.ibarometro.com/newsite/wp-content/uploads/2015/07/Radiograf \%C3 \%ADa-ideol \%C3 \%B3gica-de-los-argentinos.pdf

Jameson, F. (2003). La posmodernidad y el mercado. En S. Zizek, Ideología. Un mapa de la cuestión. Buenos Aires: Fondo de Cultura Económica.

Johnson, R. \& Wichern, D. (1998). Applied Multivariate Statistical Analysis. Upper Saddle River: Prentice Hall.

Laclau, E., y Mouffe, C. (1987). Hegemonía y estrategia socialista. Hacia una radicalización de la democracia. Madrid: Siglo XXI editores.

Lattuada, M. (1987). Política agraria del liberalismo-conservador 1946-1985. Buenos Aires: Centro Editor de América Latina. Colección Biblioteca política argentina.

Lattuada, M. (1993). Corporaciones y política agraria en la transición democrática argentina. Agricultura y Sociedad, 68-69, 159-193.

Liaudat, M. D. (2015). La construcción hegemónica de las entidades técnicas en el agro argentino: análisis de los discursos de AAPRESID y AACREA en la última década. Mundo Agrario, 16(32). Recuperado de http://www.mundoagrario.unlp.edu.ar/article/view/MAv16n32a04

Locke, J. (2003). Segundo ensayo sobre el gobierno civil. Buenos Aires: Losada.

Mora y Araujo, M. (1985). La naturaleza de la coalición alfonsinista. En N. Botana y otros, La Argentina electoral (pp. 89-107). Buenos Aires: Sudamericana.

Mosciaro, M., y Dimuro V. (2009). Zonas Agroeconómicas Homogéneas Buenos Aires Sur. Buenos Aires: INTA.

Murray, J. (2013). Likert Data: What to Use, Parametric or Non-Parametric? International Journal of Business and Social Science, 4(11), 258-264.

Norman, G. (2010). Likert scales, levels of measurement and the 'laws' of statistics. Advances in health sciences education: theory and practice, 15, 625-632. 
Nun, J. (1984). Averiguaciones sobre algunos significados del peronismo. En O. Oszlak y otros, “Proceso”, crisis y transición democrática/2. Buenos Aires: Centro Editor de America Latina, Biblioteca Política Argentina.

Nun, J. (1989). La rebelión del coro. Buenos Aires: Nueva Visión.

Phillips, L. (1998). Hegemony and Political Discourse: the lasting impact of Thatcherism. Sociology, 32(4), 847-867.

Thernborn, G. (1991). La ideología del poder y el poder de la ideología. México: Siglo XXI.

Tourangeau, R., Rips, L. J. \& Rasinski, K. (2004). The Psychology of Survey Response. Cambridge: Cambridge, University Press.

Voloshinov, V. (1929). El marxismo y la filosofía del lenguaje. Madrid: Alianza, 1992.

Zizek, S. (2003). El espectro de la ideología. En S. Zizek, Ideología. Un mapa de la cuestión. Buenos Aires: Fondo de Cultura Económica.

\section{ANEXO}

Mapa 1. Zonas agroeconómicas de la provincia de Buenos Aires relevadas en la encuesta (27 zonas excepto las marcadas con rojo o azul)

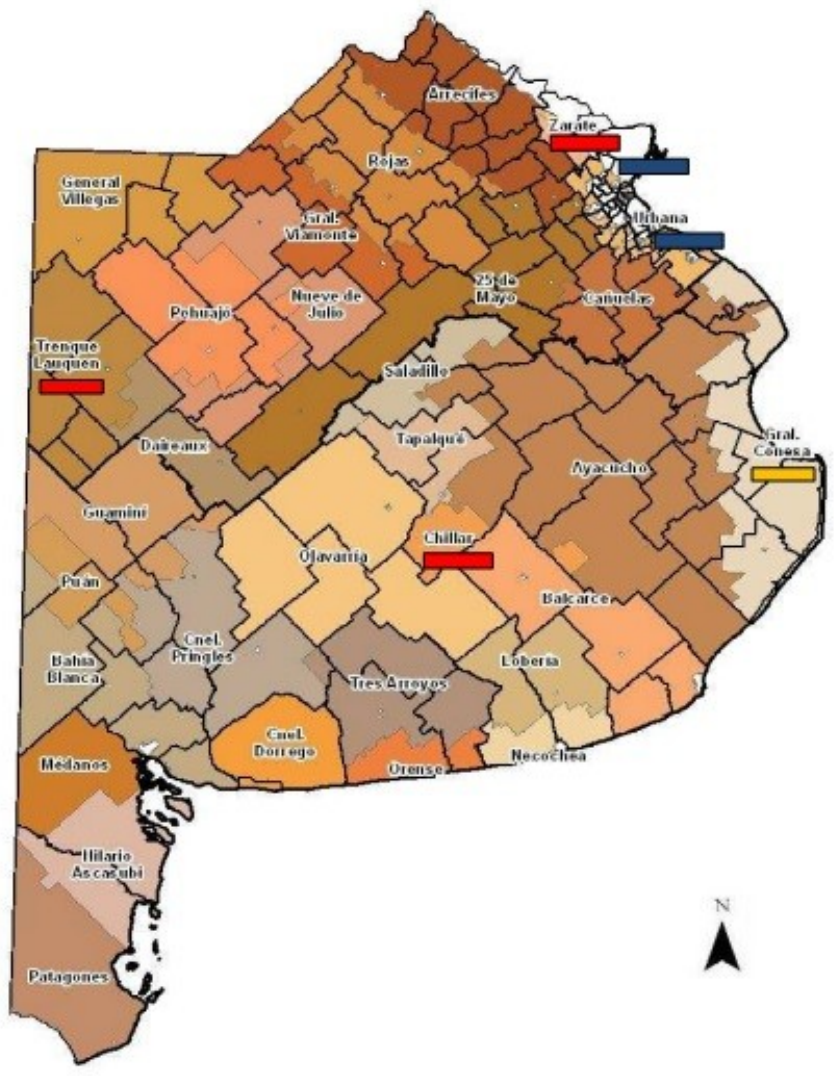


Tabla 1. Frases frente a la palabra pools de siembra

\begin{tabular}{|l|l|l|l|l|l|}
\hline \multicolumn{2}{|c|}{} & Frecuencia & Porcentaje & $\begin{array}{l}\text { Porcentaje } \\
\text { válido }\end{array}$ & $\begin{array}{l}\text { Porcentaje } \\
\text { acumulado }\end{array}$ \\
\hline Negativo y muy negativo & 201 & 53,7 & 58,2 & 58,2 \\
\hline Algo negativo & 30 & 8,2 & 8,8 & 67,0 \\
\hline Apoyado por el gobierno & 21 & 5,6 & 6,1 & 73,1 \\
\hline Descripción neutra & 60 & 16,0 & 17,3 & 90,4 \\
\hline Algo positivo & 22 & 5,8 & 6,2 & 96,6 \\
\hline Positivo & 12 & 3,1 & 3,4 & 100,0 \\
\hline Total & 345 & 92,4 & 100,0 & \\
\hline NS/NC & 28 & 7,6 & & \\
\hline Total & 374 & 100,0 & & \\
\hline
\end{tabular}

Tabla 2. Frases frente a la palabra Monsanto

\begin{tabular}{|c|c|c|c|c|c|}
\hline & & Frecuencia & Porcentaje & $\begin{array}{l}\text { Porcentaje } \\
\text { válido }\end{array}$ & $\begin{array}{l}\text { Porcentaje } \\
\text { acumulado }\end{array}$ \\
\hline \multirow{5}{*}{ Válidos } & Malo / Monopolio & 76 & 20,2 & 23,6 & 23,6 \\
\hline & $\begin{array}{l}\text { Multinacional / Mal } \\
\text { necesario }\end{array}$ & 73 & 19,5 & 22,7 & 46,3 \\
\hline & Neutro (empresa) & 57 & 15,4 & 17,9 & 64,2 \\
\hline & $\begin{array}{l}\text { Positivo, aporta tecnología, } \\
\text { líder }\end{array}$ & 115 & 30,7 & 35,8 & 100,0 \\
\hline & Total & 321 & 85,8 & 100,0 & \\
\hline Perdidos & Sistema & 53 & 14,2 & & \\
\hline \multicolumn{2}{|l|}{ Total } & 374 & 100,0 & & \\
\hline
\end{tabular}

Tabla 3. Principal diferenciación que haría entre los productores agropecuarios

\begin{tabular}{|l|l|c|c|c|c|}
\hline \multicolumn{2}{|c|}{} & Frecuencia & Porcentaje & $\begin{array}{c}\text { Porcentaje } \\
\text { válido }\end{array}$ & $\begin{array}{c}\text { Porcentaje } \\
\text { acumulado }\end{array}$ \\
\hline \multirow{5}{*}{} & Por tamaño & 143 & 38,3 & 38,6 & 38,6 \\
\cline { 2 - 6 } & Por tipo de producción & 123 & 32,9 & 33,2 & 71,8 \\
\cline { 2 - 6 } & $\begin{array}{l}\text { Viven del campo, trabajan la tierra / } \\
\text { Otros negocios, no trabajan la tierra }\end{array}$ & 55 & 14,8 & 14,9 & 86,8 \\
\cline { 2 - 6 } & Por tenencia del suelo & 6 & 1,7 & 1,7 & 88,5 \\
\cline { 2 - 6 } & Innovadores / tradicionales & 17 & 4,5 & 4,5 & 93,0 \\
\cline { 2 - 6 } & $\begin{array}{l}\text { Cuidan la tierra y el ambiente / no lo } \\
\text { hacen }\end{array}$ & 2 &, 6 &, 6 & 93,6 \\
\cline { 2 - 6 } & $\begin{array}{l}\text { Por lugar en la red (pools, rentistas, } \\
\text { contratistas, etc.) }\end{array}$ & 9 & 2,5 & 2,5 & 96,2 \\
\cline { 2 - 6 } & $\begin{array}{l}\text { No hay diferencias, tienen los mismos } \\
\text { intereses }\end{array}$ & 14 & 3,8 & 3,8 & 100,0 \\
\cline { 2 - 6 } & Total & 370 & 99,1 & 100,0 & \\
\hline Perdidos & Sistema & 4 &, 9 & & \\
\hline Total & & 374 & 100,0 & & \\
\hline
\end{tabular}


Tabla 4. Conceptualización y opinión sobre la frase La tierra para el que la trabaja

\begin{tabular}{|c|c|c|c|c|c|}
\hline & & Frequencia & Porcentaje & $\begin{array}{l}\text { Porcentaje } \\
\text { válido }\end{array}$ & $\begin{array}{l}\text { Porcentaje } \\
\text { acumulado }\end{array}$ \\
\hline & Entiende el significado y lo apoya & 85 & 22,7 & 23,2 & 23,2 \\
\hline & $\begin{array}{l}\text { Entiende y está medianamente de } \\
\text { acuerdo, o contra lo extranjero, o } \\
\text { colonización sin expropiación }\end{array}$ & 20 & 5,4 & 5,6 & 28,7 \\
\hline & $\begin{array}{l}\text { Entiende y acuerda pero solo en } \\
\text { términos utópioss }\end{array}$ & 19 & 5,2 & 5,3 & 34,0 \\
\hline & $\begin{array}{l}\text { Resignifica (tiene que ser trabajada, } \\
\text { sacar ganancia, eficientemente, esté en } \\
\text { el campo, sentimental) y apoya }\end{array}$ & 83 & 22,1 & 22,6 & 56,6 \\
\hline & $\begin{array}{l}\text { Entiende el significado (o lo cambia) y } \\
\text { no se posiciona }\end{array}$ & 18 & 4,7 & 4,8 & 61,4 \\
\hline & Resignifica pero igual no acuerda & 14 & 3,7 & 3,8 & 65,2 \\
\hline & Entiende el significado y está en contra & 120 & 32,0 & 32,7 & 97,9 \\
\hline & No entiende el significado & 8 & 2,0 & 2,1 & 100,0 \\
\hline & Total & 366 & 97,9 & 100,0 & \\
\hline & NS/NC & 8 & 2,1 & & \\
\hline Total & & 374 & 100,0 & & \\
\hline
\end{tabular}

Tabla 5. Grado de acuerdo con las frases liberal-conservadoras

\begin{tabular}{|l|c|c|c|}
\hline & $\begin{array}{c}\text { El derecho de la propiedad de } \\
\text { la tierra es sagrado y } \\
\text { debe ser siempre respetado } \\
\text { por el Estado \% }\end{array}$ & $\begin{array}{c}\text { Solo los productores } \\
\text { deben decidir qué y cómo } \\
\text { se produce en su tierra \% }\end{array}$ & $\begin{array}{c}\text { Los mercados tienen que estar } \\
\text { completamente desregulados \% }\end{array}$ \\
\hline Totalmente & 87,7 & 74,7 & 44,5 \\
\hline Medianamente & 10,5 & 16,6 & 34,8 \\
\hline Solo un poco & 1,2 & 4,6 & 13,4 \\
\hline Nada & 0,6 & 4,1 & 7,2 \\
\hline
\end{tabular}

Tabla 6. Grado de acuerdo con las frases tecnologizantes

\begin{tabular}{|l|l|l|l|c|}
\hline & $\begin{array}{l}\text { Las nuevas } \\
\text { tecnologías } \\
\text { mejoraron mu cho } \\
\text { la situación de } \\
\text { todos los } \\
\text { productores } \\
\text { rurales \% }\end{array}$ & $\begin{array}{l}\text { Hoy en el campo } \\
\text { argentino el más } \\
\text { competitivo no es el } \\
\text { más grande, sino el } \\
\text { que mejor sabe } \\
\text { hacer \% }\end{array}$ & $\begin{array}{l}\text { Los productores } \\
\text { agropecuarios ya no } \\
\text { son chacareros sino } \\
\text { que son empresarios } \\
\%\end{array}$ & $\begin{array}{l}\text { Dentro de la cadena } \\
\text { agroindustrial, los } \\
\text { productores agropecuarios, } \\
\text { los industriales y } \\
\text { comerciantes tienen los } \\
\text { mismos intereses \% }\end{array}$ \\
\hline Totalmente & 54,9 & 51,3 & 27,5 & 18,1 \\
\hline Medianamente & 24,7 & 36,2 & 27,7 & 22,3 \\
\hline Solo un poco & 17,2 & 9,6 & 20,3 & 21,6 \\
\hline Nada & 3,2 & 2,8 & 24,5 & 38,1 \\
\hline
\end{tabular}


Tabla 7. Grado de acuerdo con las frases agraristas y contra tecnologizantes

\begin{tabular}{|c|c|c|c|c|c|c|c|}
\hline & $\begin{array}{l}\text { Son } \\
\text { necesarias } \\
\text { leyes que } \\
\text { frenen la } \\
\text { concentra- } \\
\text { ción de la } \\
\text { tierra yque } \\
\text { limiten la } \\
\text { expansión } \\
\text { de la } \\
\text { agricultura } \\
\text { en gran } \\
\text { escala } \%\end{array}$ & $\begin{array}{l}\text { Hay que } \\
\text { mantener las } \\
\text { retenciones pero } \\
\text { usarlas para } \\
\text { sacarle más a } \\
\text { las grandes } \\
\text { cerealeras y } \\
\text { agroindustrias y } \\
\text { darle créditos } \\
\text { baratos a los } \\
\text { productores } \\
\text { familiares } \%\end{array}$ & $\begin{array}{l}\text { El Estado tiene } \\
\text { que regular el } \\
\text { mercado de los } \\
\text { arrendamientos } \\
\text { para evitar } \\
\text { precios } \\
\text { exorbitantes } \%\end{array}$ & $\begin{array}{l}\text { Los verdaderos } \\
\text { productores } \\
\text { son los que } \\
\text { trabajan } \\
\text { efectivamente } \\
\text { en el campo } \%\end{array}$ & $\begin{array}{c}\text { Muchos } \\
\text { pequeños } \\
\text { productores } \\
\text { han } \\
\text { desaparecido } \\
\text { a causa del } \\
\text { cambio } \\
\text { tecnológico }\end{array}$ & $\begin{array}{c}\text { El Estado } \\
\text { debería } \\
\text { volver a } \\
\text { regular los } \\
\text { mercados } \\
\text { con Juntas } \\
\text { de carnes } \\
\text { ygranos } \\
\%\end{array}$ & $\begin{array}{c}\text { El Estado } \\
\text { debe regular } \\
\text { el uso del } \\
\text { suelo para } \\
\text { evitar que se } \\
\text { deteriore un } \\
\text { recurso que } \\
\text { es de todos } \\
\text { los } \\
\text { argentinos \% }\end{array}$ \\
\hline Totalmente & 47,4 & 45,3 & 16,8 & 44,9 & 31,2 & 28,7 & 36,6 \\
\hline Medianamente & 31,7 & 25,2 & 25,3 & 31,7 & 22,8 & 18,7 & 22,2 \\
\hline Solo un poco & 12,1 & 15,4 & 14,6 & 11,6 & 30,1 & 13,4 & 17,0 \\
\hline Nada & 8,8 & 14,2 & 43,3 & 11,7 & 15,9 & 38,9 & 24,3 \\
\hline
\end{tabular}

Tabla 8. Porcentaje del total de entrevistados según sus respuestas a los ejes agrarista/liberal y tecnologizante/crítico, y numeración de los tipos ideológicos

\begin{tabular}{|l|l|c|c|c|}
\hline & & \multicolumn{3}{|c|}{ Eje liberal-conservador / agrarista } \\
\hline & & $\begin{array}{c}\text { Agrarista } \\
\text { (Tipo } \\
\text { ideológico) }\end{array}$ & $\begin{array}{c}\text { Neutro } \\
\text { liberal/agrarista } \\
\text { (Tipo } \\
\text { ideológico) }\end{array}$ & $\begin{array}{c}\text { Liberal- } \\
\text { conservador } \\
\text { (Tipo } \\
\text { ideológico) }\end{array}$ \\
\hline \multirow{3}{*}{$\begin{array}{l}\text { Eje tecnologizante / crítico } \\
\text { tecnológico }\end{array}$} & Crítico tecnológico & $\begin{array}{c}4,8 \% \\
\mathbf{( 1 )}\end{array}$ & $\begin{array}{c}10,6 \% \\
(\mathbf{2})\end{array}$ & $\begin{array}{c}12,7 \% \\
\mathbf{( 3 )}\end{array}$ \\
\cline { 2 - 5 } & $\begin{array}{l}\text { Neutro } \\
\text { tecnologizante }\end{array}$ & $\begin{array}{c}6,0 \% \\
\mathbf{( 4 )}\end{array}$ & $\begin{array}{c}15,4 \% \\
\mathbf{( 5 )}\end{array}$ & $\begin{array}{c}19,0 \% \\
\mathbf{( 6 )}\end{array}$ \\
\cline { 2 - 5 } & Tecnologizante & $\begin{array}{c}3,6 \% \\
(\mathbf{7})\end{array}$ & $\begin{array}{c}5,7 \% \\
\mathbf{( 8 )}\end{array}$ & $\begin{array}{c}21,8 \% \\
\mathbf{( 9 )}\end{array}$ \\
\hline
\end{tabular}

Tabla 9. Tipos ideológicos según frases y palabras vinculadas con Pools de siembra \% dentro de Tipos según frases

\begin{tabular}{|c|c|c|c|c|c|c|c|c|}
\hline & \multicolumn{6}{|c|}{ Pools } & \multirow[b]{2}{*}{$\begin{array}{c}\text { Total } \\
\%\end{array}$} \\
\hline & & $\begin{array}{c}\text { Negativo } \\
\text { y muy } \\
\text { negativo } \\
\%\end{array}$ & $\begin{array}{c}\text { Algo } \\
\text { negativo } \\
\%\end{array}$ & $\begin{array}{c}\text { Apoyado } \\
\text { por el } \\
\text { gobierno } \\
\%\end{array}$ & $\begin{array}{c}\text { Descripción } \\
\text { neutra \% }\end{array}$ & $\begin{array}{c}\text { Algo } \\
\text { positivo } \\
\%\end{array}$ & $\begin{array}{l}\text { Positivo } \\
\%\end{array}$ & \\
\hline 1 & Agrarista y Crítico tecnológico & 71,4 & 7,1 & 7,1 & 14,3 & & & 100,0 \\
\hline 2 & Crítico tecnológico y Neutro ag/lib & 71,4 & 7,1 & & 21,4 & & & 100,0 \\
\hline 3 & Liberal.conserv y Critico tecnológico & 54,1 & 10,8 & 13,5 & 16,2 & 5,4 & & 100,0 \\
\hline 4 & Agrarista y Neutro tecnolvcrit & 35,0 & 20,0 & & 45,0 & & & 100,0 \\
\hline 5 & Neutro lib/ag y Neutro tecn/crit & 64,0 & 12,0 & 2,0 & 16,0 & 6,0 & & 100,0 \\
\hline 6 & Liberal-conserv. y Neutro tecn/crit & 50,8 & 11,9 & 6,8 & 18,6 & 6,8 & 5,1 & 100,0 \\
\hline 7 & Agrarista y Tecnologizante & 66,7 & & & 16,7 & & 16,7 & 100,0 \\
\hline 8 & Tecnologizante y Neutro ag/lib & 41,2 & 11,8 & 11,8 & 23,5 & 5,9 & 5,9 & 100 \\
\hline 0 & Liberal-conserv. y Tecnologizante & 60,0 & 5,7 & 1,4 & 12,9 & 15,7 & 4,3 & 100,0 \\
\hline & Total & 57,3 & 9,8 & 4,6 & 18,6 & 6,8 & 2,9 & 100,0 \\
\hline
\end{tabular}


Tabla 10. Tipos ideológicos según frases y palabras vinculadas con Monsanto \% dentro de Tipos según frases

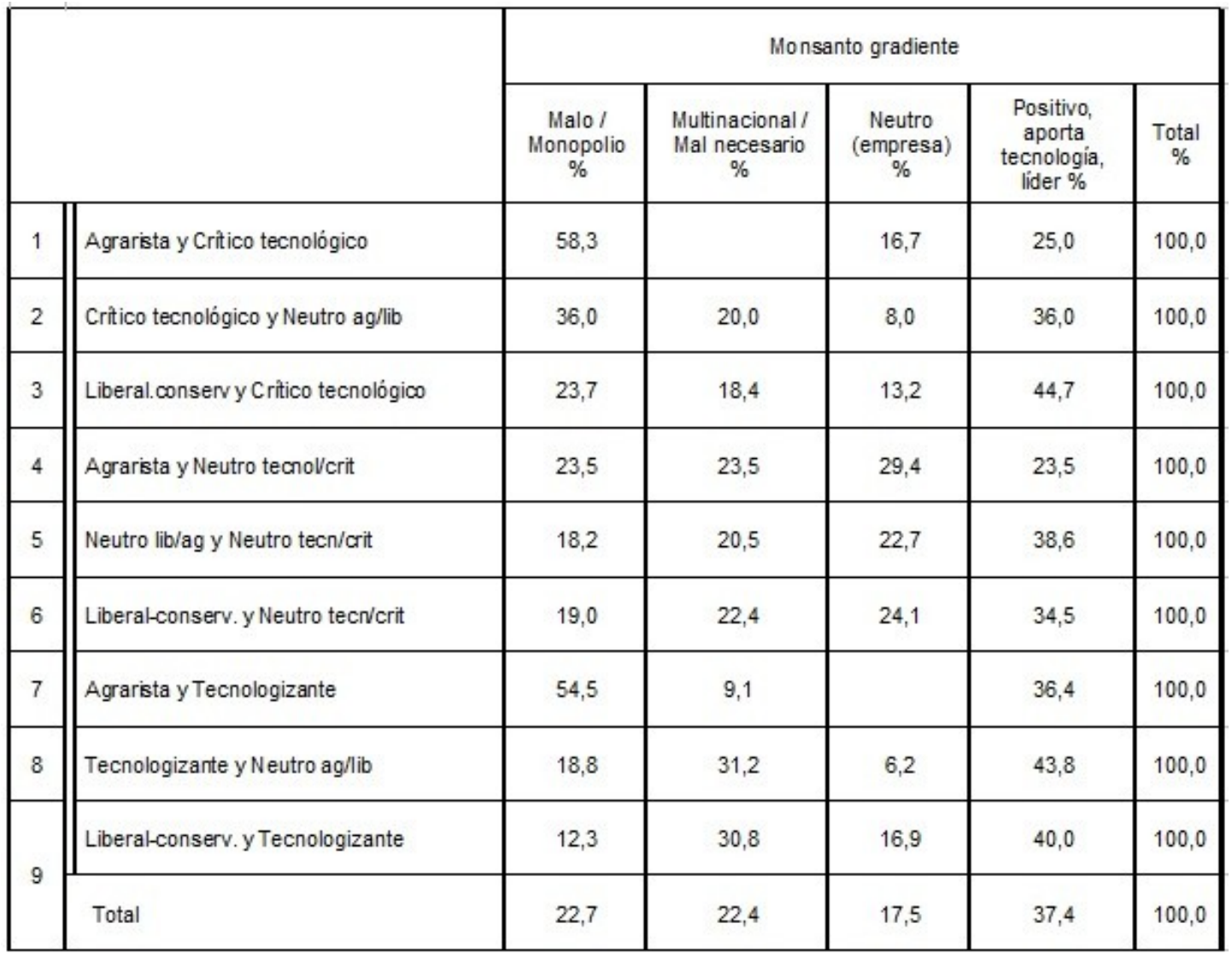

Tabla 11. Tipos ideológicos según frases y respuestas a La tierra para el que la trabaja \% dentro de Tipos según frases

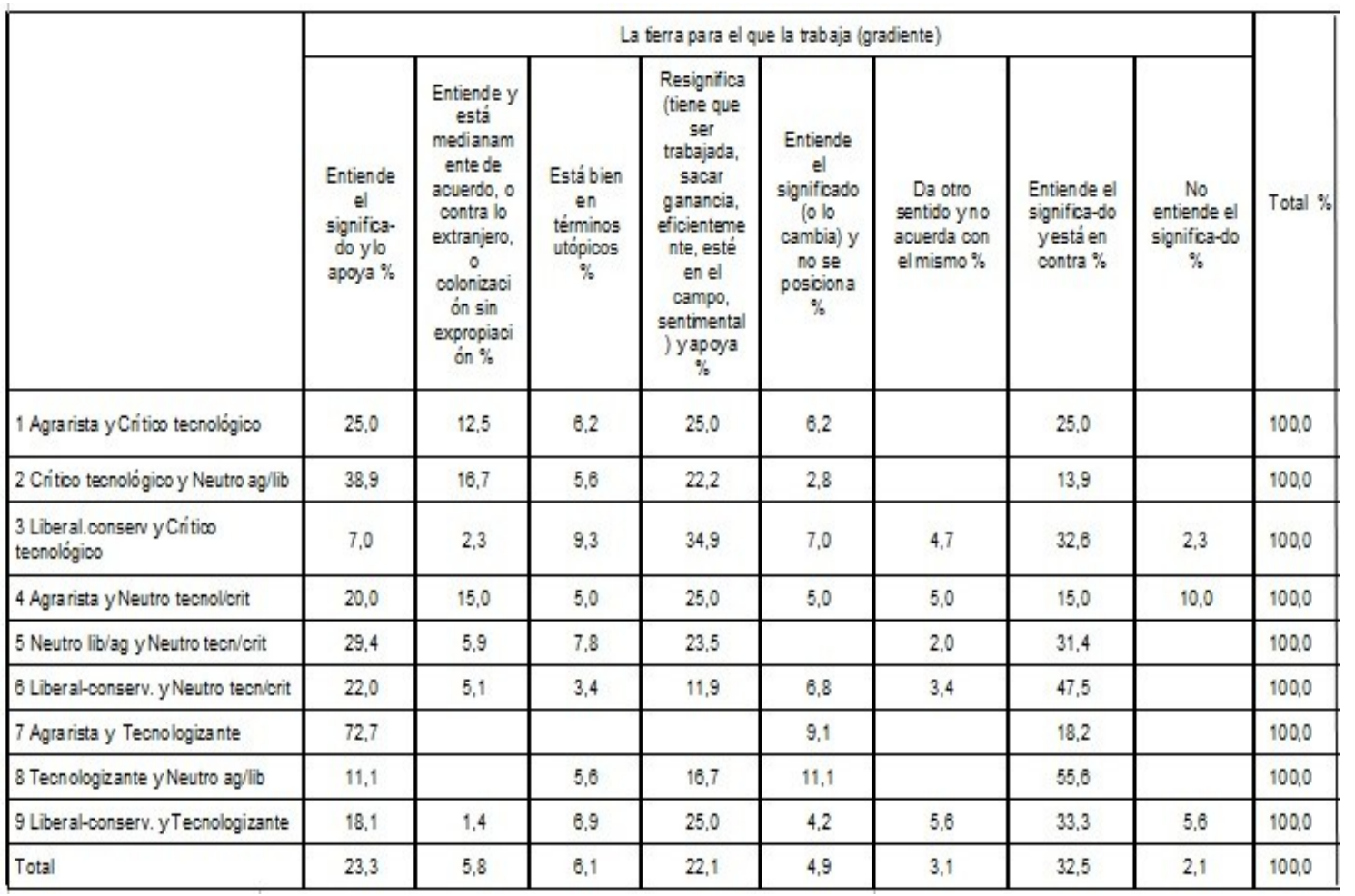


Tabla 12. Voto a diputados nacionales en 2009 según Tipos ideológicos en el eje liberal / agrarista $\%$ dentro de Tipos en el eje liberal / agrarista

\begin{tabular}{|c|c|c|c|c|c|}
\hline & & & s en el eje & eral/ agrarista & \\
\hline & & Agrarista \% & Neutro $\%$ & Liberal-conservador \% & \\
\hline & De Narváez & 19,5 & 31,5 & 43,4 & 36,2 \\
\hline & Kirchner & 29,3 & 12,4 & 5,3 & 11,0 \\
\hline & Stolbizer & 36,6 & 39,3 & 40,1 & 39,4 \\
\hline & Sabbatella & 7,3 & 6,7 & 3,3 & 5,0 \\
\hline & En blanco & 2,4 & 3,4 & 2,0 & 2,5 \\
\hline & Nulo & & & 0,7 & 0,4 \\
\hline & No votó & 2,4 & 2,2 & 1,3 & 1,8 \\
\hline & Otro & 2,4 & 4,5 & 3,9 & 3,9 \\
\hline Total & & 100,0 & 100,0 & 100,0 & 100,0 \\
\hline
\end{tabular}

Tabla 13. Voto presidencial en 2011 según Tipos ideológicos en el eje liberal / agrarista $\%$ dentro de Tipos en el eje liberal / agrarista

\begin{tabular}{|c|c|c|c|c|c|}
\hline & \multicolumn{3}{|c|}{ Tipos en el eje liberal / agrarista } & \multirow[b]{2}{*}{ Total \% } \\
\hline & & $\begin{array}{l}\text { Agrarista } \\
\%\end{array}$ & Neutro \% & $\begin{array}{l}\text { Liberat- } \\
\text { conservador \% }\end{array}$ & \\
\hline \multirow{11}{*}{ Voto 2011} & CFK & 35,7 & 6,7 & 1,3 & 8,1 \\
\hline & Binner & 42,9 & 34,8 & 32,0 & 34,5 \\
\hline & Alfonsín & 9,5 & 27,0 & 29,4 & 25,7 \\
\hline & Rodríguez Saa & & 5,6 & 4,6 & 4,2 \\
\hline & Duhalde & 2,4 & 9,0 & 15,0 & 11,3 \\
\hline & Altamira & & 3,4 & 0,7 & 1,4 \\
\hline & Carrió & 9,5 & 10,1 & 12,4 & 11,3 \\
\hline & En blanco & & & 1,3 & 0,7 \\
\hline & Nulo & & & 0,7 & 0,4 \\
\hline & No votó & & 3,4 & 0,7 & 1,4 \\
\hline & Otros & & & 2,0 & 1,1 \\
\hline \multicolumn{2}{|l|}{ Total } & 100,0 & 100,0 & 100,0 & 100,0 \\
\hline
\end{tabular}


Tabla 14. Porcentaje de identificación con los intereses de los distintos tipos de productores. Total de entrevistados

\begin{tabular}{|l|c|c|c|c|c|}
\hline & Iguales & $\begin{array}{c}\text { Un poco } \\
\text { distintos }\end{array}$ & $\begin{array}{c}\text { Bastante } \\
\text { distintos }\end{array}$ & $\begin{array}{c}\text { Muy } \\
\text { distintos }\end{array}$ & Subtotal \\
\cline { 2 - 6 } & $\begin{array}{c}\% \text { dela } \\
\text { fila }\end{array}$ & $\begin{array}{c}\% \text { de la } \\
\text { fila }\end{array}$ & $\begin{array}{c}\% \text { de la } \\
\text { fila }\end{array}$ & $\begin{array}{c}\% \text { de la } \\
\text { fila }\end{array}$ & $\%$ de la fila \\
\hline $\begin{array}{l}\text { Un gran estanciero, con } 5.000 \text { hectáreas y } 5.000 \\
\text { vacunos }\end{array}$ & $7,7 \%$ & $13,4 \%$ & $16,4 \%$ & $62,4 \%$ & $100,0 \%$ \\
\hline $\begin{array}{l}\text { Un dueño de un gran pool de siembra, que } \\
\text { organiza la agricultura en } 50.000 \text { hectáreas }\end{array}$ & $1,6 \%$ & $4,1 \%$ & $14,9 \%$ & $79,4 \%$ & $100,0 \%$ \\
\hline $\begin{array}{l}\text { Un productor agropecuario dueño de } 500 \\
\text { hectáreas y que toma en arriendo otras } 500\end{array}$ & $30,6 \%$ & $30,0 \%$ & $17,0 \%$ & $22,4 \%$ & $100,0 \%$ \\
\hline $\begin{array}{l}\text { Un productor dueño de 200 hectáreasy que } \\
\text { toma en arriendo } 100\end{array}$ & $45,3 \%$ & $31,6 \%$ & $13,8 \%$ & $9,3 \%$ & $100,0 \%$ \\
\hline $\begin{array}{l}\text { Un pequeño chacarero que arrienda unas } 100 \\
\text { hectáreas en la región pampeana }\end{array}$ & $36,2 \%$ & $24,5 \%$ & $15,9 \%$ & $23,4 \%$ & $100,0 \%$ \\
\hline $\begin{array}{l}\text { Un campesino de Santiago del Estero que no } \\
\text { tiene título de propiedad y lucha por la tierra }\end{array}$ & $8,3 \%$ & $8,2 \%$ & $12,0 \%$ & $71,5 \%$ & $100,0 \%$ \\
\hline
\end{tabular}

Tabla 15. Sentido de separación según tamaño de las unidades productivas \% dentro de Escalas de tamaño

\begin{tabular}{|l|l|c|c|c|}
\hline \multicolumn{2}{|c|}{} & \multicolumn{2}{|c|}{ Separa } & \multirow{2}{*}{ Total \% } \\
\cline { 2 - 5 } & $\begin{array}{c}\text { Sin sentido de } \\
\text { separación \% }\end{array}$ & $\begin{array}{c}\text { Con sentido de } \\
\text { separación \% }\end{array}$ & \\
\hline \multirow{5}{*}{ Escalas de tamaño } & menos de 50 ha & 8,6 & 91,4 & 100,0 \\
\cline { 2 - 5 } & de 50 a 200 ha & 30,4 & 69,6 & 100,0 \\
\cline { 2 - 5 } & de 200 a 500 ha & 29,4 & 70,6 & 100,0 \\
\cline { 2 - 5 } & de 500 a 1000 ha & 35,4 & 64,6 & 100,0 \\
\cline { 2 - 5 } & de 1000 a 2000 ha & 35,3 & 64,7 & 100,0 \\
\cline { 2 - 5 } & más de 2000 ha & 72,7 & 27,3 & 100,0 \\
\hline \multirow{2}{*}{ Total } & 30,7 & 69,3 & 100,0 \\
\hline
\end{tabular}

Tabla 1. Matriz de correlaciones de las 14 frases

Tabla 2. Valor medio y desvío estándar de las respuestas a las frases, según cada uno de los tipos ideológicos 